\title{
Emerging Role of LncRNAs in Ischemic Stroke- Novel Insights into the Regulation of Inflammation
}

\author{
Yongli Pan (D) ${ }^{1} *$ \\ Qingzheng Jiao ${ }^{2, *}$ \\ Wei Wei ${ }^{3, *}$ \\ Tianyang Zheng ${ }^{4, *}$ \\ Xinyu Yang ${ }^{5}$ \\ Wenqiang $X$ in (i) $^{5}$ \\ 'Department of Neurology, Weifang \\ Medical University, Weifang, Shandong, \\ People's Republic of China; ${ }^{2}$ Second \\ Department of Internal Medicine, \\ Gucheng County Hospital, Gucheng, \\ Hebei, People's Republic of China; \\ ${ }^{3}$ Department of Neurology, Mianyang \\ Central Hospital, Mianyang, Sichuan, \\ People's Republic of China; ${ }^{4}$ Department \\ of Neurosurgery, The First Hospital of \\ jilin University, Changchun, Jilin, People's \\ Republic of China; ${ }^{5}$ Department of \\ Neurosurgery, Tianjin Medical University \\ General Hospital, Tianjin, People's \\ Republic of China
}

*These authors contributed equally to this work
Correspondence: Wenqiang Xin Department of Neurosurgery, Tianjin Medical University General Hospital, Anshan Road No. I54, Tianjin, 300052 People's Republic of China

Tel +86-185 2620I I 82

Fax +86-22 60362062

Email xinwenqiangdr@।26.com

\begin{abstract}
As a crucial kind of pervasive gene, long noncoding RNAs (lncRNAs) are abundant and key players in brain function as well as numerous neurological disorders, especially ischemic stroke. The mechanisms underlying ischemic stroke include angiogenesis, autophagy, apoptosis, cell death, and neuroinflammation. Inflammation plays a vital role in the pathological process of ischemic stroke, and systemic inflammation affects the patient's prognosis. Although a great deal of research has illustrated that various lncRNAs are closely relevant to regulate neuroinflammation and microglial activation in ischemic stroke, the specific interactional relationships and mechanisms between lncRNAs and neuroinflammation have not been described clearly. This review aimed to summarize the therapeutic effects and action mechanisms of lncRNAs on ischemia by regulating inflammation and microglial activation. In addition, we emphasize that lncRNAs have the potential to modulate inflammation by inhibiting and activating various signaling pathways, such as microRNAs, NF- $\kappa \mathrm{B}$ and ERK.
\end{abstract}

Keywords: ischemic stroke, long noncoding RNA, microglia, neuroinflammation

\section{Introduction}

Approximately $16.67 \%$ of people worldwide may experience an ischemic stroke in their lifetime, ${ }^{1}$ and such strokes are responsible for almost 6 million deaths and more than $10 \%$ of all mortalities each year; moreover, two-thirds of ischemic survivors remain disabled. ${ }^{2}$ Despite the thrombectomy and recombinant tissue plasminogen activator (rtPA) being the main accepted treatments, ${ }^{3}$ whether neuroinflammation affects the prognosis of ischemic stroke after such treatment remains controversial since stroke-induced inflammation is one of the most vital factors that limits treatment efficiency. Neuroinflammation plays a vital role in the pathological process of stroke, and systemic inflammation affects patient prognosis. ${ }^{4-6}$ Focal cerebral ischemia in animals leads to an inflammatory cascade that includes oxidative stress, excitotoxicity, inflammatory cell activation, and toxic inflammatory mediators, which in turn impair nerve tissue and cells. On the other hand, inflammation contributes greatly to the recovery of damaged tissue and cells by promoting microglia to immediately migrate to the infarction site. ${ }^{7,8}$ In the past one decade, researchers have performed many studies to explore the therapeutic potential of long noncoding RNAs (lncRNAs), which are endogenous ncRNAs $>200$ nucleotides in length that lack an open reading frame. ${ }^{9}$ LncRNAs are considered a key factor in regulating the expression and function of protein-coding genes, and they are involved in different signaling pathways of cellular processes, 
such as cell apoptosis, inflammation angiogenesis and autophagy, thereby regulating stroke prognosis. ${ }^{10}$ Previous research indicates that modulating IncRNA expression can inhibit microglial activation and improve neurological functions. ${ }^{11}$ To date, the literature investigating the interactional relationship between neuroinflammation and IncRNAs in ischemia is still limited, and the mechanisms have also not been estimated accurately. The purpose of this review is to summarize the potential therapeutic effects and pathways of lncRNAs in stroke based on their ability to regulate inflammation.

\section{Neuroinflammatory Response and Related Mechanisms in Stroke}

Neuroinflammation is integral to the poststroke pathophysiological process and causes the disruption of tissue homeostasis, ${ }^{12,13}$ including acidosis, excitotoxicity mediated by reactive oxygen species (ROS), increased cytoplasmic $\mathrm{Ca}^{2+}$ concentrations, loss of glucose and oxygen, complement activation, destruction of the blood-brain barrier (BBB), mitochondrial damage and secondary messengers by resident central nervous system (CNS) glia and endothelial cells. ${ }^{14-16}$ On the other hand, inflammation combines innate and peripheral immune responses involved in physiological brain development and different pathologic conditions, such as neurodegenerative diseases or stroke. ${ }^{17,18}$ In summary, inflammatory cells are classically involved in innate responses and activated within hours and perfectly situated to sense imbalances in the $\mathrm{CNS},{ }^{19-21}$ including natural killer cells, neutrophils, dendritic cells, macrophages, microglia and astrocytes that participate in the secretion of inflammatory chemokines and the selective recognition and clearance of pathogens and toxic cell debris during infection or tissue injury. ${ }^{22-24}$

During the early phase of stroke, the peripheral immune responses of inflammation initiate immediately at a second massive cascade of inflammation, and different damageassociated molecular patterns (DAMPs), such as high mobility group box 1 , heat shock proteins, interleukin-33, purines (ATP and UTP), mitochondrial-derived $\mathrm{N}$-formyl peptides and peroxiredoxins, can gain access to the systemic circulation. ${ }^{25-27}$ These molecules activate pattern recognition receptors on microglia and astrocytes and on brain resident immune cells, ${ }^{27,28}$ and subsequently, the activation of endothelial cells aggravates BBB breakdown, thus allowing peripheral leukocytes to arrive in the injured area. ${ }^{29-31}$ Due to the disruption of the BBB, DAMPs and cytokines induce a response of the immune system in primary and secondary lymphoid organs, which leads to systemic inflammatory response syndrome and activates some inflammatory pathways, such as mitogen-activated protein kinase (MAPK) and nuclear factor kappa-light-chain-enhancer of activated B cells $(\mathrm{NF}-\mathrm{kB}) .{ }^{32-34}$ All these factors can greatly affect the prognosis of patients. ${ }^{35,36}$ Thus, exposing the role and mechanism of inflammation and identifying a treatment for the recovery of stroke have been driving forces for extensive studies in recent decades.

\section{Significant Role of Long Noncoding RNAs in Cerebral Ischemia Essential Characteristics and Associated Functions of LncRNAs}

LncRNAs are a type of RNA defined as transcripts with a length of $>200$ nucleotides that are not directly translated into proteins. ${ }^{37}$ These transcripts regulate the expression of genes through affecting epigenetics, transcription, and translation, playing important physiological and pathological roles, and participating in various signaling pathways underlying multiple diseases. ${ }^{38}$ LncRNAs are located in the nucleus or cytoplasm and regulate the expression of genes at the transcriptional or posttranscriptional level. LncRNAs in the nucleus regulate gene expression in various modes, such as isolating transcription factor/protein complexes from chromatin and gathering different proteins to form ribonucleoprotein complexes in response to stimuli. ${ }^{39}$ However, cytoplasmic lncRNAs stabilize ribonucleoprotein complexes, regulate the stability of mRNA or bind miRNAs as competitive endogenous RNAs (ceRNAs). Transcription or recruitment of chromatinmodifying enzymes to target genes induces chromosomal circulation to increase the association between enhancer and promoter regions. ${ }^{40}$ Various lncRNAs also regulate gene expression by modifying chromosome and mRNA expression, and lncRNAs even act as ceRNAs and cause RNA degradation. ${ }^{41}$

\section{LncRNAs and Cerebral Ischemia}

Increasing evidence shows that hundreds of abnormally expressed lncRNAs have been found in ischemic models and play a crucial role in the pathogenesis of stroke. ${ }^{42-44}$ LncRNA profiles have been reported to greatly influence ischemic injury progression in microvascular endothelial cells during ischemia after oxygen-glucose deprivation and reperfusion $(\mathrm{OGD} / \mathrm{R}),{ }^{45-47}$ rodent focal stroke, ${ }^{48-50}$ and 
some blood samples. ${ }^{51,52}$ Recently, several specific lncRNAs, such as H19, taurine upregulated gene 1 (TUG1), growth arrest-specific 5 (GAS5), CaMK2Drelated transcript 1 (C2dat1), small nucleolar RNA host gene 14 (SNHG14), HOXA distal transcript antisense RNA (HOTTIP), and N1LR, have been shown to be increased in ischemia. ${ }^{46,47,52-62}$ LncRNAs have been reported to stimulate apoptosis, angiogenesis, inflammation, and neuronal death after ischemic stroke. ${ }^{47,52-55,63}$ These findings demonstrate that the brain responds to stroke-associated stimuli by altering lncRNA transcriptomic profiles. These robust stroke-induced lncRNA aberrations suggest the potential functional roles and predictive value of lncRNAs as new biomarkers for stroke. An overview of how lncRNAs act on neurological recovery is given in Figure 1.

\section{LncRNAs Regulate Cell Death and Apoptosis in Cerebral Ischemia}

Numerous studies have demonstrated that changes in lncRNA levels are related to cell death after ischemic stroke. A previous study indicated that metastasis-associated lung adenocarcinoma transcript 1 (MALAT1) promotes neuronal death via targeting miR-30a in ischemic stroke. ${ }^{49}$ It protects the cerebral microvasculature and parenchyma from cerebral ischemic insults by inhibiting endothelial cell death and

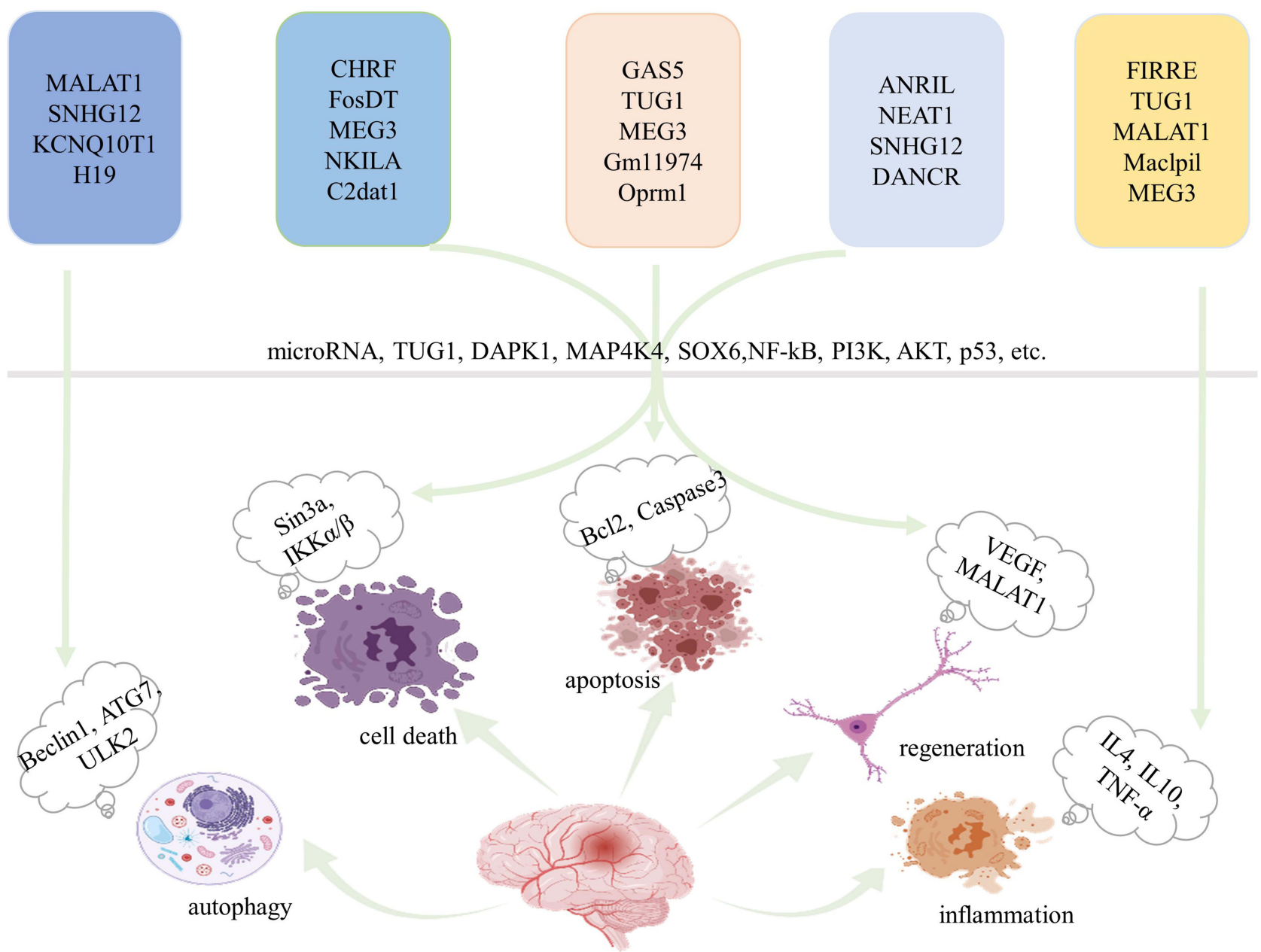

Figure I Overview of the effects of IncRNAs on neurological recovery. LncRNAs predominantly modulate autophagy, cell death, apoptosis, regeneration and inflammation through various pathways, and microRNAs are key players. Created with Biorender.com.

Abbreviations: MALATI, metastasis-associated lung adenocarcinoma transcript I; SNHGI2, small nucleolar RNA host gene I2; KCNQIOTI, potassium voltage-gated channel subfamily Q member I opposite strand I; CHRF, cardiac hypertrophy-related factor; FosDT, Fos downstream transcript; MEG3, maternally expressed gene 3; NKILA, NF-KB interacting IncRNA; C2dat I, CAMK2D-associated transcript I; GAS5, growth arrest-specific 5; TUGI, taurine-upregulated gene I; Oprm I, opioid receptor $\mu$ I gene; ANRIL, antisense noncoding RNA in the INK4 locus; NEATI, nuclear paraspeckle assembly transcript I; DANCR, differentiation antagonizing nonprotein-coding RNA; FIRRE, functional intergenic repeating RNA element; Maclpil, macrophage containing lymphocyte cytosolic protein I factor (LCPI)-related proinflammatory; DAPKI, death-associated protein kinase I; MAP4K4, mitogen-activated protein kinase 4; SOX6, sex-determining region Y-box 6; NF-KB, nuclear factor kappa B; VEGF, vascular endothelial growth factor. 
inflammation and plays roles in the progression of cerebrovascular permeability and BBB integrity after stroke. ${ }^{46}$ In addition, MALAT1 interacted with miR-26b and upregulated ULK2 expression, which in turn suppressed neuronal death. $^{47}$ In addition, N1LR and maternally expressed 3 (MEG3) also interact with neuronal death after ischemic stroke by inactivating p53. ${ }^{58}$ Knockdown of MEG3 inhibits neuronal death by targeting the miR-21/PDCD4 signaling pathway. ${ }^{54}$ Consistent with these findings, growth arrestspecific 5 (GAS5) inhibits cell death and increases neuronal survival by targeting the miR-137/Notch1 signaling pathway, ${ }^{57}$ small nucleolar RNA host gene 14 (SNHG) mediated by hypoxia-inducible factor- $1 \alpha$ (HIF-1 $\alpha)$ and vascular endothelial growth factor (VEGF) signaling acts as a ceRNA for miR-18a, thereby affecting cerebral infarction. ${ }^{60}$ To date, a series of preclinical studies have assessed the effects of IncRNAs on regulating cell death in ischemia models.

Among the various programmed cell death pathways, ${ }^{64}$ apoptosis accounts for a large proportion of neuronal death through brain ischemia, ${ }^{65}$ which efficiently removes damaged cells from DNA damage or during development. ${ }^{66}$ Apoptosis plays a pivotal role in the homeostasis of normal tissues, and researchers have recently found that IncRNAs have essential effects on regulating cell apoptosis following stroke. ${ }^{67}$ LncRNA growth arrest-specific 5 (GAS5), a ceRNA for miR137, was upregulated and negatively correlated with miR137 expression in stroke mice and OGD/R-treated primary neurons. ${ }^{68}$ Chen et $\mathrm{l}^{69}$ illustrated that lncRNA TUG1 was significantly upregulated in ischemia in an MCAO model. TUG1 has been proven to interact with miR-9 and decrease $\mathrm{Bcl} 2$ protein, which activates bax and ultimately leads to neuronal apoptosis. ${ }^{70}$ Overexpression of lncRNA opioid receptor $\mu 1$ gene (Oprm1) attenuated apoptosis-induced cerebral injury via the Oprm1/miR-155/GATA3 axis by reducing cleaved caspase- 3 levels. ${ }^{71}$ One study illustrated that lncRNA rhabdomyosarcoma 2-associated transcript (RMST) promoted OGD-induced injury in brain microvascular endothelial cells by regulating the miR204-5p/VCAM1 pathway. ${ }^{72}$ To date, a great number of studies have assessed the effect of IncRNAs on regulating apoptosis in ischemia. The characteristics of some of these studies are summarized in Table 1.

\section{LncRNAs Regulate Angiogenesis in Cerebral Ischemia}

During angiogenesis, the blood supply recovers in damaged regions after ischemia, thus alleviating ischemic necrosis by assisting the brain in restoring collateral circulation. ${ }^{73}$ Current studies have indicated that several lncRNAs play a vital role in regulating endothelial cell survival, vascular integrity, and angiogenesis in ischemia. Numerous lncRNAs are associated with angiogenesis after stroke by affecting transcription and translation. ${ }^{74}$ A recent study found that the overexpression of MEG3 suppresses functional recovery after ischemia, the silencing of MEG3 ameliorates brain lesions, and the expression of MEG3 increases angiogenesis after ischemia by promoting endothelial cell migration, proliferation, sprouting, and tube formation by regulating the Notch pathway. ${ }^{75}$ Furthermore, another study demonstrated that IncRNA Aerrie and SNHG12 contribute to DNA signaling and repair mechanisms and relieve endothelial cell injury after ischemic stroke. ${ }^{76-78}$ In addition, another clinical study demonstrated that lncRNA MACC1-AS1 also exerts a protective role after stroke. ${ }^{74}$ To date, a range of preclinical studies have assessed the effect of lncRNAs on regulating neurogenesis and angiogenesis in cerebral ischemia. The characteristics of some of these studies are summarized in Table 2.

\section{LncRNAs Regulate Autophagy in Cerebral Ischemia}

Autophagy is an evolutionarily conserved cellular mechanism that can maintain cellular nerve homeostasis, and it is associated with degraded misfolded or nonfunctional proteins and damaged organelles. ${ }^{67,79}$ Numerous studies confirm that autophagy provides a neuroprotective effect on stroke by promoting the clearance of damaged proteins and organelles, which facilitates energy recycling and cellular defense. ${ }^{67}$ It is widely accepted that various lncRNAs affect cell survival in stroke by regulating autophagy. ${ }^{66}$ MALAT1 is one of the most significantly upregulated lncRNAs in both in vivo and in vitro models of stroke and serves as a competing endogenous RNA by sponging miR-126 to upregulate its target ULK2 under hypoxic injury based on the protective effect of autophagy. ${ }^{47}$ Similarly, lncRNA antisense noncoding RNA in the INK4 locus (ANRIL) and lncRNA FosDT were all elevated by negatively regulating miR-127 expression ${ }^{80}$ and interacting with REST-associated chromatin-modifying proteins separately to protect against ischemic stroke. ${ }^{81}$ In contrast, exogenous overexpression of H19 results in autophagic cell death in cerebral ischemia. ${ }^{82}$ Acting as a competing endogenous RNA of miR-200a, lncRNA 
Table I Preclinical and Clinical Stroke Studies Assessing the Effect of Different LncRNAs on the Regulation of Apoptosis and Cell Death

\begin{tabular}{|c|c|c|c|c|c|c|}
\hline $\begin{array}{l}\text { Author, } \\
\text { Year }\end{array}$ & LncRNA & Models & Species & Regulation & Targets & Functions \\
\hline \multicolumn{7}{|c|}{ LncRNAs regulate apoptosis in stroke } \\
\hline $\begin{array}{l}\text { Xiao et al } \\
2019\end{array}$ & $\mathrm{HI9}$ & $\begin{array}{l}\text { MCAO, } \\
\text { OGD/R }\end{array}$ & $\begin{array}{l}\text { Human, Rats, } \\
\text { Cells }\end{array}$ & Up & $\operatorname{miR}-19 a$ & $\begin{array}{l}\text { Modulate hypoxia induced neuronal } \\
\text { apoptosis }\end{array}$ \\
\hline $\begin{array}{l}\text { Wang et al } \\
2020\end{array}$ & MEG3 & $\begin{array}{l}\text { MCAO, } \\
\text { OGD/R }\end{array}$ & $\begin{array}{l}\text { Human, Mice, } \\
\text { Cells }\end{array}$ & Up & Bax, cleaved Caspase-3 & $\begin{array}{l}\text { Promote cell apoptosis and aggravates } \\
\text { hypoxia }\end{array}$ \\
\hline Xiang et al. & MEG3 & $\begin{array}{l}\text { MCAO, } \\
\text { OGD/R }\end{array}$ & Mice, Cells & Up & miR-424-5p, MAPK & Mediate neuronal apoptosis \\
\hline $\begin{array}{l}\text { Luo et al } \\
2020\end{array}$ & GAS5 & OGD/R & Human, Cells & Up & $\begin{array}{l}\text { Bax, Bcl-2, cleaved } \\
\text { caspase- } 3\end{array}$ & $\begin{array}{l}\text { Regulate neuronal apoptosis and } \\
\text { infarction size }\end{array}$ \\
\hline $\begin{array}{l}\text { Wu et al } \\
2017\end{array}$ & NILR & $\begin{array}{l}\text { MCAO, } \\
\text { OGD/R }\end{array}$ & Mice, Cells & Up & P53 & Promote neuroprotection \\
\hline $\begin{array}{l}\text { Zhou et al } \\
2020\end{array}$ & SNHG7 & $\begin{array}{l}\text { MCAO, } \\
\text { OGD/R }\end{array}$ & Mice, Cells & Down & miR-9, SIRTI & Alleviate neuronal injury \\
\hline $\begin{array}{l}\text { Jing et al } \\
2019\end{array}$ & Oprml & $\begin{array}{l}\text { MCAO, } \\
\text { OGD/R }\end{array}$ & Mice, Cells & Up & $\begin{array}{l}\text { miR-I55, GATA3, } \\
\text { Caspase-3 }\end{array}$ & Overexpression alleviates apoptosis \\
\hline $\begin{array}{l}\text { Cheng et al } \\
2020\end{array}$ & RMST & OGD/R & Cells & Up & miR-107, Bcl2, Bax, p53 & $\begin{array}{l}\text { Promote OGD-induced neuronal } \\
\text { apoptosis }\end{array}$ \\
\hline $\begin{array}{l}\text { Yao et al } \\
2019\end{array}$ & Rian & $\begin{array}{l}\text { MCAO, } \\
\text { OGD/R }\end{array}$ & Mice, Cells & Down & $\begin{array}{c}\text { miR-144-3p, caspase-3, } \\
\text { Bax, Bcl-2 }\end{array}$ & $\begin{array}{l}\text { Attenuated cell apoptosis from } \\
\text { cerebral I/R injury }\end{array}$ \\
\hline Gao et al & $\mathrm{HCP5}$ & OGD/R & Cells & Up & miR-652-3p, LC3, p62 & Protect against cerebral I/R injury \\
\hline $\begin{array}{l}\text { Cao et al } \\
2021\end{array}$ & TALNEC2 & $\begin{array}{l}\text { MCAO, } \\
\text { OGD/R }\end{array}$ & Mice, Cells & Up & miR-650, APAFI & Aggravate apoptosis cerebral I/R injury \\
\hline \multicolumn{7}{|c|}{ LncRNAs regulate cell death in stroke } \\
\hline $\begin{array}{l}\text { Yan et al } \\
2016\end{array}$ & MEG3 & $\begin{array}{l}\text { MCAO, } \\
\text { OGD/R }\end{array}$ & Rats, Cells & Up & P53 & As a cell death promoter \\
\hline $\begin{array}{l}\text { Yan et al } \\
2017\end{array}$ & MEG3 & $\begin{array}{l}\text { MCAO, } \\
\text { OGD/R }\end{array}$ & Mice, Cells & Up & miR-2I & $\begin{array}{c}\text { Target miR-2 I/PDCD4 signaling } \\
\text { pathway }\end{array}$ \\
\hline $\begin{array}{l}\text { Deng et al } \\
2019\end{array}$ & Nespas & $\begin{array}{l}\text { MCAO, } \\
\text { OGD/R }\end{array}$ & Mice, Cells & Up & $\mathrm{Bcl}-2, \mathrm{Bax}$ & $\begin{array}{c}\text { Silence aggravates } \mathrm{I} / \mathrm{R} \text {-induced ischemic } \\
\text { damage }\end{array}$ \\
\hline $\begin{array}{l}\text { Xu et al } \\
2020\end{array}$ & D63785 & OGD/R & Cells & Down & miR-422a & $\begin{array}{c}\text { Overexpression reverses neuronal cell } \\
\text { death }\end{array}$ \\
\hline $\begin{array}{l}\text { Guo et al } \\
2017\end{array}$ & MALATI & $\begin{array}{l}\text { MCAO, } \\
\text { OGD/R }\end{array}$ & Mice, Cells & Up & $\mathrm{miR}-30 \mathrm{a}$ & $\begin{array}{l}\text { Downregulation attenuates neuronal } \\
\text { cell death }\end{array}$ \\
\hline $\begin{array}{l}\text { Wang et al } \\
2018\end{array}$ & NKILA & OGD/R & Cells & Up & miR-103, miR-107 & $\begin{array}{l}\text { Upregulation mediates neuronal cell } \\
\text { death }\end{array}$ \\
\hline
\end{tabular}

Abbreviations: LncRNA, long non-coding RNA; MCAO, middle cerebral artery occlusion; OGD/R, oxygen glucose deprivation/re-oxygenation; I/R, ischemia and reperfusion; MAPK, Mitogen-activated protein kinases; APAFI, apoptotic peptidase activating factor I; MEG3, maternally expressed gene 3; PDCD4, programmed cell death 4; MALATI, metastasis associated lung adenocarcinoma transcript I; NKILA, NF-kB interacting long non-coding RNA. 
Table 2 Preclinical and Clinical Stroke Studies Assessing the Effect of Different LncRNAs on the Regulation of Neurogenesis and Angiogenesis

\begin{tabular}{|c|c|c|c|c|c|c|}
\hline $\begin{array}{l}\text { Author, } \\
\text { Year }\end{array}$ & LncRNA & Species & Models & Regulation & Targets & Main Functions \\
\hline $\begin{array}{l}\text { Wang et al } \\
2019\end{array}$ & $\mathrm{HI9}$ & Mice & MCAO & Up & Notchl, p53 & Prevent the process of neurogenesis \\
\hline $\begin{array}{l}\text { Zhang et al } \\
2020\end{array}$ & EPS & Mice & MCAO & Up & NA & Accelerate neuron regeneration \\
\hline $\begin{array}{l}\text { You et al } \\
2019\end{array}$ & MEG3 & Rats & MCAO & Up & $\begin{array}{l}\text { Wnt } / \beta \text {-catenin, } \\
\text { BDNF }\end{array}$ & $\begin{array}{l}\text { Down-regulation enhance nerve growth and alleviated } \\
\text { neurological impairment }\end{array}$ \\
\hline $\begin{array}{l}\text { Sui et al } \\
2020\end{array}$ & MEG8 & $\begin{array}{l}\text { Mice, } \\
\text { Cells }\end{array}$ & $\begin{array}{l}\text { MCAO, } \\
\text { OGD/R }\end{array}$ & Up & $\begin{array}{l}\text { miR-I30a, } \\
\text { VEGFA }\end{array}$ & Promote angiogenesis and attenuates cerebral ischemia \\
\hline $\begin{array}{l}\text { Zhao et al } \\
2018\end{array}$ & SNHGI 2 & $\begin{array}{l}\text { Mice, } \\
\text { Cells }\end{array}$ & $\begin{array}{l}\text { MCAO, } \\
\text { OGD/R }\end{array}$ & Up & $\begin{array}{l}\text { miR-I50, } \\
\text { VEGF }\end{array}$ & Promote the angiogenesis \\
\hline $\begin{array}{l}\text { Yan et al } \\
2020\end{array}$ & $\begin{array}{l}\text { MACCI- } \\
\text { ASI }\end{array}$ & Cells & OGD/R & Down & $\begin{array}{l}\text { miR-68675p, } \\
\text { VEGFA }\end{array}$ & $\begin{array}{c}\text { Attenuates microvascular endothelial cell injury and } \\
\text { promotes angiogenesis }\end{array}$ \\
\hline $\begin{array}{l}\text { Zhang et al } \\
2019\end{array}$ & DANCR & Cells & OGD/R & Up & $\begin{array}{l}\text { miR-33a-5p, } \\
\quad \text { XBPIs }\end{array}$ & Enhanced survival and angiogenesis \\
\hline $\begin{array}{l}\text { Wang et al } \\
2018\end{array}$ & SNHGI & Cells & OGD/R & Up & $\begin{array}{l}\text { miR-I99, } \\
\text { VEGFA }\end{array}$ & $\begin{array}{l}\text { Upregulation promotes the angiogenesis of brain } \\
\text { microvascular endothelial cells }\end{array}$ \\
\hline $\begin{array}{l}\text { Li et al } \\
2017\end{array}$ & $\begin{array}{l}\text { HIF-IA- } \\
\text { AS2 }\end{array}$ & $\begin{array}{l}\text { Mice, } \\
\text { Cells }\end{array}$ & $\begin{array}{l}\text { PMCAO, } \\
\text { OGD/R }\end{array}$ & Up & $\begin{array}{l}\text { miR-I55, } \\
\text { VEGFA }\end{array}$ & Influence angiogenesis in hypoxia \\
\hline
\end{tabular}

Abbreviations: LncRNA, long non-coding RNA; NA, not available; MCAO, middle cerebral artery occlusion; OGD/R, oxygen glucose deprivation/re-oxygenation; MEG3, maternally expressed gene 3; BDBF, brain-derived neurotrophic factor; VEGF, vascular endothelial growth factor; XBPI, X-box-binding protein I; PMCAO, permanent middle cerebral artery occlusion.

KCNQ1OT1 is significantly upregulated in ischemic stroke and increased the infarct volume and neurological impairments in mice induce transient middle cerebral artery occlusion (MCAO). ${ }^{83}$ To date, a vast number of studies have assessed the effect of lncRNAs on regulating autophagy in ischemia. The characteristics of some of these studies are summarized in Table 3.

\section{LncRNAs Regulate Neuroinflammation in}

\section{Cerebral Ischemia}

Data from four electronic databases, PubMed, Cochrane Library, EMBASE, and Web of Science, were retrieved to identify all literature (clinical and preclinical) evaluated the effect of IncRNAs on the regulation of neuroinflammation in stroke conditions. Two independent authors (YLP and WQX) searched for related publications using the following keywords in combination with Boolean logic: ("noncoding RNA" or "IncRNA") and ("inflammation" or "microglia") and ("ischemia" or "ischemic" or "stroke" or "hypoxia"). In addition, reference lists were manually checked to identify other potential literature associated with the effect of IncRNAs on neuroinflammation. Finally, a total of 39 studies that included 27 kinds of lncRNAs were identified. ${ }^{1,84-121}$ Of these 39 articles, ten studies focused on clinical research, twenty-nine studies focused on preclinical stroke, and nearly half of them focused on microglial functions. More details are shown in Table 4.

\section{LncRNAs Modulate Inflammation and Regulate Microglia Activation in Preclinical Stroke Studies}

The inflammatory response is a double-edged sword after ischemia because it not only intensifies secondary injury to the brain but also promotes the recovery of neurological function, thus revealing that inflammation is associated with the pathogenesis and prognosis of ischemia. A large number of studies have illustrated that various lncRNAs are closely associated with the regulation of inflammation and microglial activation in ischemia. ${ }^{66}$ Several studies have revealed that knocking down lncRNA MALAT1 reduces inflammatory damage after ischemia by Myd88 
Table 3 Preclinical and Clinical Stroke Studies Assessing the Effect of Different LncRNAs on the Regulation of Autophagy

\begin{tabular}{|c|c|c|c|c|c|c|}
\hline $\begin{array}{l}\text { Author, } \\
\text { Year }\end{array}$ & LncRNA & Models & Species & Regulation & Targets & Main Functions \\
\hline $\begin{array}{l}\text { Yu et al } \\
2019\end{array}$ & KCNQIOTI & $\begin{array}{l}\text { tMCAO, } \\
\text { OGD/R }\end{array}$ & $\begin{array}{l}\text { Human, } \\
\text { Mice, Cells }\end{array}$ & Up & $\begin{array}{l}\text { miR-200a, } \\
\text { FOXO3, ATG7 }\end{array}$ & $\begin{array}{l}\text { Knockdown inhibits autophagy and increase cell } \\
\text { viability }\end{array}$ \\
\hline $\begin{array}{l}\text { Luo et al } \\
2020\end{array}$ & MEG3 & $\begin{array}{l}\text { MCAO, } \\
\text { OGD/R }\end{array}$ & Mice, Cells & Up & $\begin{array}{l}\text { miR-378, Beclin I, } \\
\text { LC3 }\end{array}$ & $\begin{array}{l}\text { MEG3/miR-378/GRB2 protected against neuronal } \\
\text { autophagy }\end{array}$ \\
\hline $\begin{array}{l}\text { Yao et al } \\
2019\end{array}$ & SNHGI 2 & $\begin{array}{l}\text { MCAO, } \\
\text { OGD/R }\end{array}$ & Mice, Cells & $U_{p}$ & Beclin I, LC3, p62 & $\begin{array}{l}\text { Up-regulation of SNHGI } 2 \text { induce autophagy } \\
\text { activation }\end{array}$ \\
\hline $\begin{array}{l}\text { Wu et al } \\
2020\end{array}$ & SNHGI 2 & OGD/R & Cells & $U_{p}$ & SIRTI, FOXO3a & $\begin{array}{l}\text { Knockdown inhibits SIRTI/FOXO3a signaling- } \\
\text { mediated autophagy }\end{array}$ \\
\hline $\begin{array}{l}\text { Gao et al } \\
2020\end{array}$ & LNHG3 & $\begin{array}{l}\text { tMCAO, } \\
\text { OGD/R }\end{array}$ & Mice, Cells & $U_{p}$ & $\begin{array}{l}\text { miR-485, LC3, } \\
\text { Beclin I }\end{array}$ & $\begin{array}{l}\text { Knockdown improve brain I/R injury to restrain } \\
\text { autophagy }\end{array}$ \\
\hline $\begin{array}{l}\text { Li et al } \\
2017\end{array}$ & MALATI & OGD/R & Mice, Cells & Up & $\begin{array}{l}\mathrm{miR}-26 \mathrm{~b}, \mathrm{LC}-3 \\
\mathrm{p} 62\end{array}$ & $\begin{array}{c}\text { MALATI promote BMEC autophagy and survival } \\
\text { under OGD/R condition }\end{array}$ \\
\hline $\begin{array}{l}\text { Wang } \\
\text { et al } 2019\end{array}$ & MALATI & OGD/R & Cells & $U_{p}$ & $\begin{array}{c}\text { miR-300c-3p, p62 } \\
\text { LC3 }\end{array}$ & $\begin{array}{l}\text { MALATI activate autophagy and promoted cell } \\
\text { survival under hypoxic condition }\end{array}$ \\
\hline $\begin{array}{l}\text { Guo et al } \\
2021\end{array}$ & MIAT & $\begin{array}{l}\text { MCAO, } \\
\text { OGD/R }\end{array}$ & Rats, Cells & $U_{p}$ & LC3, p62 & $\begin{array}{c}\text { MIAT promote autophagy of neural cells and } \\
\text { aggravate ischemic stroke }\end{array}$ \\
\hline $\begin{array}{l}\text { Xu et al } \\
2021\end{array}$ & C2dat2 & $\begin{array}{l}\text { MCAO, } \\
\text { OGD/R }\end{array}$ & Mice, Cells & $U_{p}$ & $\begin{array}{l}\text { miR-30d-5p, LC3 } \\
\text { Beclin I, p62 }\end{array}$ & $\begin{array}{c}\text { C2dat2/miR-30d-5p/DDIT4/mTOR facilitate } \\
\text { autophagy }\end{array}$ \\
\hline
\end{tabular}

Abbreviations: LncRNA, long non-coding RNA; MCAO, middle cerebral artery occlusion; tMCAO, transient middle cerebral artery occlusion; OGD/R, oxygen glucose deprivation/re-oxygenation; I/R, ischemia and reperfusion; FOXO3, forkhead box O3; MEG3, maternally expressed gene 3; BMEC, Brain microvascular endothelial cell; CIRI, cerebral ischemia-reperfusion injury.

signaling while overexpressing lncRNA MALAT1 is positively associated with higher levels of interleukin (IL-1 $\beta$ ), tumor necrosis factor $\alpha$ (TNF- $\alpha$ ) and IL- $6 .{ }^{122}$ H19 is one of the most representative lncRNA genes that can be activated after hypoxia, and it can potentially increase inflammation. $^{123}$ Knockdown of lncRNA H19 in the MCAO model promoted cerebral recovery, increased plasma IL-10 levels, and reduced TNF- $\alpha$ and IL-1 $\beta$ levels. ${ }^{121}$ Higher lncRNA H19 levels in stroke participants inhibited the recovery of neurological function and were associated with the levels of TNF- $\alpha .^{123}$

Normally, microglia are the main resident immune cells and contain a ramified structure to maintain homeostasis in the area surrounding microglial cells. Microglia in the central nervous system are activated immediately when ischemic stroke occurs. ${ }^{124}$ Microglial activation is the first step of the inflammatory response, and then other immune cells, such as neutrophils, $\mathrm{T}$ cells, and natural killer cells, are activated in the brain. ${ }^{125,126}$ There are dual subtypes of microglia in the pathological process of stroke, including M1 and M2 microglia. ${ }^{127,128}$ M1 microglia exacerbate brain damage by producing IL-6, IL-1 $\beta$, nitric oxide (NO), TNF- $\alpha$, etc., while M2 microglia repair the brain by secreting IL-4, IL-10, and transforming growth factor (TGF- $\beta$ ). ${ }^{129,130}$ A series of studies provided the initial evidence that IncRNA SNHG14 and SNHG4 are highly expressed under ischemic conditions and upregulate the expression of inflammation-related cell pathways, such as signal transducer and activator of transcription (STAT) 6 and AQP4, by regulating miR-145-5p and miR-199b, thus leading to the microglial activation in cerebral infarction. ${ }^{110,131,132}$ By regulating Kruppel-like factor 4 and protein kinase B (AKT)/STAT3 cell pathway, lncRNA MEG3 and nuclear paraspeckle assembly transcript 1 (NEAT1) affect microglial polarization and the levels of proinflammatory and anti-inflammatory factors. $^{133,134}$ Finally, the inhibition of H19 also can reduce activation of microglia and promote microglial M2 polarization.

\section{LncRNA Regulation Correlates with the Level of Inflammatory Cytokines in Stroke Patients}

In the pathogenesis of ischemic conditions, the inflammatory response is regarded as one of the most 
Table 4 Preclinical and Clinical Stroke Studies Assessing the Effect of LncRNA on the Regulation of Inflammation

\begin{tabular}{|c|c|c|c|c|c|c|c|c|}
\hline $\begin{array}{l}\text { Author, } \\
\text { Year }\end{array}$ & LncRNA & Provenance & Cell & Expression & $\begin{array}{l}\text { Signaling } \\
\text { Pathways }\end{array}$ & Microglia & $\begin{array}{l}\text { Inflammatory } \\
\text { Factors }\end{array}$ & Model \\
\hline $\begin{array}{l}\text { Cao et al } \\
2020\end{array}$ & MALATI & Mice, Cells & BV2 & Decrease & $\begin{array}{c}\text { miR- }|8| c-5 p / \\
\text { HMGBI }\end{array}$ & Activation & $\begin{array}{c}\text { IL-I } \beta, \text { IL-6, TNF- } \alpha \text {, } \\
\text { IL-I0 }\end{array}$ & MCAO \\
\hline $\begin{array}{l}\text { Zhang } \\
\text { et al } 2017\end{array}$ & MALATI & Mice, Cells & $\begin{array}{l}\text { Mouse } \\
\text { BMECs }\end{array}$ & Increase & NA & NA & $\begin{array}{l}\text { MCP-I, IL-6, and } \\
\text { E-selectin }\end{array}$ & $\begin{array}{l}\text { MACO, } \\
\text { OGD/R }\end{array}$ \\
\hline $\begin{array}{l}\text { Ren et al } \\
2020\end{array}$ & MALATI & Human & Blood & Decrease & NA & NA & $\begin{array}{l}\text { CRP, TNF-a, IL-6, } \\
8,10,17,22\end{array}$ & AIS \\
\hline $\begin{array}{l}\text { Ruan et al } \\
2018\end{array}$ & MALATI & Rats, Cells & rBMVECs & Increase & $\begin{array}{c}\text { CREB/PGC- } \mid \alpha / \\
\text { PPAR } \gamma\end{array}$ & NA & TNF-a, IL-6, IL-I $\beta$ & $\begin{array}{l}\text { tMCAO, } \\
\text { OGD/R }\end{array}$ \\
\hline $\begin{array}{l}\text { Wang } \\
\text { et al } 2017\end{array}$ & MALATI & Rats, Cells & Microglia & Increase & $\begin{array}{c}\text { MyD88/IRAKI/ } \\
\text { TRAF6 }\end{array}$ & Activation & IL-I $\beta$, IL-6, TNF- $\alpha$ & MCAO \\
\hline $\begin{array}{l}\text { Zhong } \\
\text { et al } 2019\end{array}$ & SNHGI4 & Rats, Cells & $\mathrm{PCI} 2$ & Increase & $\begin{array}{l}\text { miR-I36-5p/ } \\
\text { ROCKI }\end{array}$ & NA & IL-I $\beta$, IL-6, TNF- $\alpha$ & $\begin{array}{l}\text { MCAO, } \\
\text { OGD/R }\end{array}$ \\
\hline $\begin{array}{l}\text { Qi et al } \\
2020\end{array}$ & SNHGI4 & Mice, Cells & BV2 & Increase & $\begin{array}{l}\text { miR- } 145-5 \mathrm{p} / \\
\text { PLA2G4A }\end{array}$ & Activation & TNF- $\alpha$ & $\begin{array}{l}\text { MCAO, } \\
\text { OGD/R }\end{array}$ \\
\hline $\begin{array}{l}\text { Zhang } \\
\text { et al 202I }\end{array}$ & SNHG I 4 & Mice, Cells & BV2 & Increase & miR-199b/AQP4 & Activation & IL-I $\beta$, TNF- $\alpha$ & $\begin{array}{l}\text { MCAO, } \\
\text { OGD/R }\end{array}$ \\
\hline $\begin{array}{l}\text { Lv et al } \\
2020\end{array}$ & SNHGI & Cells & $\begin{array}{l}\text { HCMIEC/ } \\
\text { D3 }\end{array}$ & Decrease & $\begin{array}{c}\mathrm{miR}-376 \mathrm{a} / \mathrm{CBS} / \\
\mathrm{H} 2 \mathrm{~S}\end{array}$ & NA & IL-6, IL-I $\beta$, TNF- $\alpha$ & OGD/R \\
\hline $\begin{array}{l}\text { Zhang } \\
\text { et al } 2020\end{array}$ & SNHG4 & Human, Rats & $\begin{array}{l}\text { Blood, } \\
\text { HEK293 }\end{array}$ & Increase & $\begin{array}{l}\text { miR-449c-5p/ } \\
\text { STAT6 }\end{array}$ & Activation & $\begin{array}{c}\mathrm{IL}-\mathrm{I} \beta, \mathrm{TNF}-\alpha, \mathrm{IL}-4, \\
6,10\end{array}$ & $\begin{array}{c}\text { AIS, } \\
\text { MCAO, } \\
\text { OGD/R }\end{array}$ \\
\hline $\begin{array}{l}\text { Guo et al } \\
2020\end{array}$ & SNHGI5 & Mice, /Cells & $\mathrm{N} 2 \mathrm{a}$ & Increase & $\begin{array}{c}\text { miR-I8a/ } \\
\text { CXXLI3/ERK/ } \\
\text { MEK }\end{array}$ & NA & TNF-a, IL-I $\beta$ & $\begin{array}{l}\text { MCAO, } \\
\text { OGD/R }\end{array}$ \\
\hline $\begin{array}{l}\text { Hu et al } \\
2021\end{array}$ & SNHGI5 & Mice, Cells & $\begin{array}{l}\mathrm{HT} 22, \\
\mathrm{BV} 2\end{array}$ & Increase & $\begin{array}{l}\text { miR-302a-3p/ } \\
\text { STATI/NF-кB }\end{array}$ & Activation & IL-I $\beta$, IL-6, TNF- $\alpha$ & $\begin{array}{l}\text { MCAO, } \\
\text { OGD/R }\end{array}$ \\
\hline $\begin{array}{l}\text { Xu et al } \\
2021\end{array}$ & $\mathrm{HI9}$ & Mice, Cells & HT22 & Increase & $\begin{array}{c}\text { miR-29b/SIRTI/ } \\
\text { PGC-I } \alpha\end{array}$ & NA & $\begin{array}{c}\text { IL-6, I } \beta, \text { I0, TNF- } \\
\alpha, \text { TGF- } \beta \text { I }\end{array}$ & $\begin{array}{l}\text { MCAO, } \\
\text { OGD/R }\end{array}$ \\
\hline $\begin{array}{l}\text { Li et al } \\
2020\end{array}$ & $\mathrm{HIO}$ & Rats, Cells & $\mathrm{PCI} 2$ & Increase & miR-I38-5p/p65 & NA & IL-6, IL-I $\beta$, TNF- $\alpha$ & $\begin{array}{l}\text { tMCAO } \\
\text { OGD/R }\end{array}$ \\
\hline $\begin{array}{l}\text { Wang } \\
\text { et al } 2017\end{array}$ & $\mathrm{HIO}$ & $\begin{array}{l}\text { Human, } \\
\text { Mice, Cells }\end{array}$ & $\begin{array}{l}\text { Blood, } \\
\text { BV2 }\end{array}$ & Increase & $\mathrm{HDACl}$ & Polarization & IL-I $\beta$, TNF- $\alpha$, IL-I0 & $\begin{array}{l}\text { MCAO, } \\
\text { OGD/R }\end{array}$ \\
\hline $\begin{array}{l}\text { Zhang } \\
\text { et al 202I }\end{array}$ & NEATI & Rats & Neuron & Increase & miR-22-3p & NA & IL-I $\beta$, IL-I8 & $\begin{array}{l}\text { MCAO, } \\
\text { OGD/R }\end{array}$ \\
\hline $\begin{array}{l}\text { Li et al } \\
2019\end{array}$ & NEATI & Human & Blood & Increase & $\begin{array}{l}\operatorname{miR} 124 \\
\operatorname{miR} I 25 a\end{array}$ & NA & $\begin{array}{c}\text { IL-6, } 8,10,17,22 \\
\text { I } \beta, \text { TNF- } \alpha\end{array}$ & AIS \\
\hline $\begin{array}{l}\text { Ni et al } \\
2020\end{array}$ & NEATI & Human & $\begin{array}{c}\text { Blood, } \\
\text { BV2, N2a }\end{array}$ & Increase & NA & Activation & $\begin{array}{c}\text { CDI6, 32, 86, } \\
\text { BDNF, PDGF, Arg- } \\
\text { I }\end{array}$ & $\begin{array}{c}\text { AIS, OGD } \\
\text { R }\end{array}$ \\
\hline
\end{tabular}


Table 4 (Continued).

\begin{tabular}{|c|c|c|c|c|c|c|c|c|}
\hline $\begin{array}{l}\text { Author, } \\
\text { Year }\end{array}$ & LncRNA & Provenance & Cell & Expression & $\begin{array}{l}\text { Signaling } \\
\text { Pathways }\end{array}$ & Microglia & $\begin{array}{l}\text { Inflammatory } \\
\text { Factors }\end{array}$ & Model \\
\hline $\begin{array}{l}\text { Li et al } \\
2020\end{array}$ & MEG3 & Mice, Cells & BV2 & Increase & KLF4 & Polarization & $\begin{array}{c}\text { IL-4, IL-I } \beta \text {, TNF- } \alpha \text {, } \\
\text { IL-I0 }\end{array}$ & $\begin{array}{l}\text { MCAO, } \\
\text { OGD/R }\end{array}$ \\
\hline $\begin{array}{l}\text { Liang et al } \\
2019\end{array}$ & MEG3 & Rats, Cells & Cells & Increase & miR-485/AIM2 & NA & IL-I $\beta$, IL-I8 & $\begin{array}{l}\text { MCAO, } \\
\text { OGD/R }\end{array}$ \\
\hline $\begin{array}{l}\text { Wen et al } \\
2017\end{array}$ & Gm4419 & Cells & Microglia & Increase & $N F-\kappa B$ & Activation & $\begin{array}{c}\text { TNF- } \alpha, \text { IL-I } \beta \text {, and } \\
\text { IL-6 }\end{array}$ & OGD/R \\
\hline $\begin{array}{l}\text { Kuai et al } \\
2021\end{array}$ & THRIL & Rats, Cells & SH-SY5Y & Increase & $\begin{array}{l}\text { miR-24-3p/ } \\
\text { NRPI/NF-кB }\end{array}$ & NA & IL-6, IL-I $\beta$, TNF- $\alpha$ & $\begin{array}{l}\text { MCAO, } \\
\text { OGD/R }\end{array}$ \\
\hline $\begin{array}{l}\text { Chen } \\
\text { et al 202I }\end{array}$ & OIP5-ASI & Human, Rats & $\begin{array}{l}\text { Blood, } \\
\text { BV2 }\end{array}$ & Decrease & $\begin{array}{c}\text { miR-186-5p/ } \\
\text { CTRP3 }\end{array}$ & Activation & TNF- $\alpha$, IL-I $\beta$, IL-6 & $\begin{array}{c}\text { AIS, OGD/ } \\
\text { R }\end{array}$ \\
\hline $\begin{array}{l}\text { Zhang } \\
\text { et al } 2019\end{array}$ & I8I0034EI4Rik & Mice, Cells & Microglia & Decrease & NA & activation & $\begin{array}{c}\text { TNF- } \alpha, \text { IL-I } \beta, 4,6 \\
\text { and } 10\end{array}$ & $\begin{array}{l}\text { MCAO, } \\
\text { OGD/R }\end{array}$ \\
\hline $\begin{array}{l}\text { Tian et al } \\
2020\end{array}$ & Snhg8 & Mice, Cells & Microglial & Decrease & $\begin{array}{l}\text { miR-425-5p/ } \\
\text { SIRTI/NF-אB }\end{array}$ & Activation & TNF- $\alpha$, IL-I $\beta$, IL-6 & $\begin{array}{l}\text { MCAO, } \\
\text { OGD/R }\end{array}$ \\
\hline $\begin{array}{l}\text { Wang } \\
\text { et al } 2019\end{array}$ & TUGI & Cells & $\begin{array}{l}\text { BV2, SH- } \\
\text { SY5Y }\end{array}$ & Increase & $\begin{array}{c}\text { miR- } 145 a-5 p / \\
\text { NF- } \kappa B\end{array}$ & Polarization & TNF- $\alpha$, IL-6, IL-I0 & OGD/R \\
\hline $\begin{array}{l}\text { Wang } \\
\text { et al } 2020\end{array}$ & EPS & Mice & $\begin{array}{l}\text { NSC, } \\
\text { microglia }\end{array}$ & Increase & NA & Migration & $\begin{array}{c}\text { TNF- } \alpha, \text { IL-I } \beta \text {, and } \\
\text { IL-6 }\end{array}$ & tMCAO \\
\hline $\begin{array}{l}\text { Gao et al } \\
2019\end{array}$ & FALI & Cells & HBMVECs & Decrease & PAKI/AKT & NA & IL-6, MCP-I & OGD/R \\
\hline $\begin{array}{l}\text { Hao et al } \\
2021\end{array}$ & TTTYI5 & Cells & $\mathrm{PCl} 2$ & Increase & miR-766-5p & NA & $\begin{array}{l}\text { TNF- } \alpha, \text { IL-I } \beta, \text { IL- } \\
\quad 18, \text { IL- } 10\end{array}$ & OGD/R \\
\hline $\begin{array}{l}\text { Yi et al } \\
2020\end{array}$ & KCNQIOTI & Human & $\begin{array}{l}\text { Blood, } \\
\mathrm{PCI} 2\end{array}$ & Increase & miR-140-3p & NA & IL-I $\beta$, TNF- $\alpha$, IL-6 & $\begin{array}{c}\text { AIS, OGD/ } \\
\text { R }\end{array}$ \\
\hline $\begin{array}{l}\text { Zhang ert } \\
\text { al. } 2019\end{array}$ & ITSNI-2 & Human & Blood & Increase & $\begin{array}{l}\text { miR-I07, miR- } \\
\text { |25a, miR-|46a }\end{array}$ & NA & $\begin{array}{c}\text { TNF- } \alpha, \text { IL-I } \beta, 6,8 \\
I 7,22\end{array}$ & AIS \\
\hline $\begin{array}{l}\text { Chen } \\
\text { et al 202I }\end{array}$ & U90926 & Mice, Cells & $\begin{array}{l}\text { Microglia, } \\
\text { BV2 }\end{array}$ & Increase & $\mathrm{MDH} 2 / \mathrm{CXCL} 2$ & NA & $\begin{array}{c}\text { CD45, Ilb, 19, 8, } \\
\text { Ly6G, }\end{array}$ & $\begin{array}{l}\text { tMCAO, } \\
\text { OGD/R }\end{array}$ \\
\hline $\begin{array}{l}\text { Wang } \\
\text { et al 202I }\end{array}$ & Fender & Mice, Cells & BV2 & Increase & HERC2/NLRC4 & NA & IL-I $\beta$, IL-I8 & $\begin{array}{l}\text { MCAO, } \\
\text { OGD/R }\end{array}$ \\
\hline $\begin{array}{l}\text { Wang } \\
\text { et al 202I }\end{array}$ & SOX2OT & Rats, Cells & $\mathrm{PCl} 2$ & Increase & $\begin{array}{c}\text { miR-135a-5p/ } \\
\text { NR3C2 }\end{array}$ & NA & IL-I $\beta$, IL-6 & $\begin{array}{l}\text { MCAO, } \\
\text { OGD/R }\end{array}$ \\
\hline $\begin{array}{l}\text { Wang } \\
\text { et al 2021 }\end{array}$ & XIST & Mice, Cells & $\mathrm{PCl} 2$ & Increase & $\begin{array}{l}\text { miR-362/ } \\
\text { ROCK2 }\end{array}$ & NA & IL-I $\beta$, IL-6, TNF- $\alpha$ & $\begin{array}{l}\text { MCAO, } \\
\text { OGD/R }\end{array}$ \\
\hline $\begin{array}{l}\text { Zhang } \\
\text { et al } 2020\end{array}$ & ZFASI & Rats, Cells & $\mathrm{PCI} 2$ & Decrease & miR-582-3p & NA & $\begin{array}{c}\text { IL-I } \beta, \text { MCP-I, } \\
\text { TNF- } \alpha\end{array}$ & $\begin{array}{l}\text { MCAO, } \\
\text { OGD/R }\end{array}$ \\
\hline $\begin{array}{l}\text { Wang } \\
\text { et al } 2020\end{array}$ & Maclpil & Mice, Cells & Cells & Increase & LCPI & NA & IL-I $\beta$, IL-4 & MCAO \\
\hline
\end{tabular}


Table 4 (Continued).

\begin{tabular}{|c|c|c|c|c|c|c|c|c|}
\hline $\begin{array}{l}\text { Author, } \\
\text { Year }\end{array}$ & LncRNA & Provenance & Cell & Expression & $\begin{array}{l}\text { Signaling } \\
\text { Pathways }\end{array}$ & Microglia & $\begin{array}{l}\text { Inflammatory } \\
\text { Factors }\end{array}$ & Model \\
\hline $\begin{array}{l}\text { Feng et al } \\
2018\end{array}$ & ANRIL & Human & Blood & Decrease & NA & NA & $\begin{array}{c}\text { IL-6, 8, I0, I7, IL- } \\
I \beta, \text { TNF- } \alpha\end{array}$ & AIS \\
\hline $\begin{array}{l}\text { Ren et al } \\
2020\end{array}$ & UCAI & Human & Blood & Increase & NA & NA & IL-6, IL-I7 & AIS \\
\hline
\end{tabular}

Abbreviations: NA, not available; MALATI, metastasis-associated lung adenocarcinoma transcript I; HMGBI, high-mobility group box I; IL, interleukin; TNF, tumor necrosis factor; MCAO, middle cerebral artery occlusion; BMECs, brain microvascular endothelial cells; MCPI, monocyte chemoattractant protein I; CRP, C-reactive protein; AIS, acute ischemic stroke; rBMVECs, rat brain microvascular endothelial cells; CREB, cAMP response element binding; PGC-I $\alpha$, peroxisome proliferator-activated receptor gamma co-activator I $\alpha$; PPAR $\gamma$, peroxisome proliferative activated receptor $\gamma$; tMCAO, transient middle cerebral artery occlusion; FALI, focally amplified IncRNA on chromosome I; HBMVECs, human primary brain microvascular endothelial cells; MCP-I, monocyte chemotactic protein-I; OGD, oxygen-glucose deprivation; SNHG, small nucleolar RNA host gene; CXCLI3, CXC chemokine ligand 13; ERK, extracellular signal-regulated kinase; MEK, mitogen- activated protein kinase; NF- $\mathrm{BB}$, nuclear factor- $\mathrm{K} B$; HCMIEC/D3, human cerebral microvascular endothelial cell line; TTTYI5, testis-specific transcript Y-linked I5; THRIL, HNRNPL related immunoregulatory long non-coding RNA; NRPI, neuropilin-I; SIRTI, silent mating-type information regulation 2 homolog I; TGF, transforming growth factor; HDACs, histones catalyzed by histone deacetylases; MEG3, maternally expressed gene 3; KLF4, Krüppel-like factor 4; YYI, Yin Yang I; FGF2I, fibroblast growth factor 2I; LCPI, lymphocyte cytosolic protein I; NR3C2, nuclear receptor subfamily 3 group $C$ member 2; ROCK2, Rho-related coiled-coil containing protein kinase 2; ITSNI-2, intersectin I-2; OIP5-ASI, Opa-interacting protein 5 antisense RNA I; CTRP3, CIq/TNF-related protein 3; Snhg8, Small nucleolar RNA host gene 8; TUGI, taurine up-regulated gene I; NSC, neural stem cell.

essential pathogenetic processes and an indicator for the development of cerebral arterial emboli. ${ }^{135}$ To date, however, the association between varied lncRNAs and stroke risk and severity, as well as the expression of cytokines related to inflammation in stroke patients, remains unknown. A rigorous search of publications on the expression of various lncRNAs in clinical studies published in three electronic databases, namely, PubMed, the Web of Science and EMBASE, until May 31, 2021, identified 6 studies that included 966 participants. ${ }^{100-105}$ Several lncRNAs have been revealed as novel biomarkers that predict higher or lower stroke risk and contribute to the evaluation of disease severity, inflammation level, and prognosis in stroke participants. ${ }^{136}$ Ren et al illustrated that IncRNA MALAT1 decreased and revealed a strong relationship with ischemic conditions, and a higher level was positively associated with a changed National Institutes of Health Stroke Scale (NIHSS) score and induced IL-10 in 200 ischemic stroke cases. $^{102}$ A dominant upregulation of KCNQ1OT1 in ischemic participant plasma and an $\mathrm{OGD} / \mathrm{R}$ model in PC12 cells contributes to the higher expression of eNOS through the miR-40-3p/hypoxia-inducible factor- $1 \alpha$ axis and is reversed by lncRNA KCNQ1OT1 knockdown and miR-140-3p overexpression. ${ }^{104}$ The short duration of follow-up, the small sample size of patients, the utilization of only plasma, and lack of detail on the molecular mechanisms are still the primary limitations of current trials.
LncRNA-microRNA-mRNA Axis is the Key Player in Regulating Inflammation Upon Ischemic Stroke

MiRNAs belong to a subtype of noncoding RNAs of approximately 22 nucleotides that have a stabilizing effect on mRNA, interact with target genes via degradation or suppression of mRNAs, and then inhibit gene translation. ${ }^{137}$ MiRNAs can act as mediators in regulating multiple target genes, and one target gene is always modulated by multiple miRNAs. ${ }^{138}$ LncRNAs are the widest subtype of noncoding RNAs, and they have direct 'sponging-like effects' on miRNAs, ${ }^{139}$ which in turn regulates the transcriptional and epigenetic levels of target genes through imperfect complementarity targeting the 3-UTR of mRNA. Some lncRNAs bind to mRNAs, thereby competing directly with miRNAs. ${ }^{137}$ The IncRNAmicroRNA-mRNA axis, therefore, contributes to the regulation of disease. Current evidence has shown that the anti- or proinflammatory effects of specific miRNAs are highly regulated by lncRNAs after ischemic stroke. LncRNA SNHG14 modulates microglial activation and achieves its proinflammatory ability by sponging miR136-5p, miR-145-5p, and miR-199b. ${ }^{110,117,140}$ Knockdown of lncRNA H19 increased functional recovery after cerebral ischemia by targeting miR-29b and miR$138-5 \mathrm{p}^{90,141}$ and promoted microglial M2 polarization due to its stimulative effect on HDAC1. ${ }^{121}$ Several studies have shown that miR-145 functions as an inflammatory mediator, while miR-145 overexpression has the potential to suppress inflammatory injury after ischemic stroke. ${ }^{112}$ LncRNA TUG1 is able to bind to miR-145a-5p directly, 
while the protective effects of lncRNA TUG1 knockdown are reversed by miR-145a-5p siRNA, demonstrating a negative association between TUG1 and miR-145a$5 \mathrm{p} .{ }^{112}$ Different signaling pathways describing the process of regulation of inflammation by the IncRNA-miRNAmRNA axis is shown in Figure 2.

LncRNAs Regulate Inflammation Through the TRAF, STAT, and NF-KB Pathways Upon Ischemic Stroke

$\mathrm{NF}-\mathrm{KB}$ is present in almost all kinds of cells and mainly acts as a transcription factor. It plays a key role in various biological processes, including inflammation, stress response, B cell development and lymphoid organ formation. ${ }^{142} \mathrm{NF}-$ $\mathrm{\kappa B}$ is reported to promote various proinflammatory mediators, and inhibition of NF- $\mathrm{KB}$ signaling has beneficial effects in cerebral stroke. ${ }^{143}$ LncRNA Snhg8 serves as a competitive endogenous RNA by sponging miR-425-5p, and a bioinformatics analysis showed that this process promotes inflammation by the NF- $\mathrm{kB}$ pathway, which was confirmed in microglia. ${ }^{11}$ Similarly, Kuai et al illustrated that lncRNA THRIL was negatively correlated with recovery of rat neurological functioning and affected ischemia-reperfusion injury-induced neuronal apoptosis and inflammatory response by regulating NF- $\mathrm{kB}$ through miR-24-3p. ${ }^{89}$ However, the following question remains: how can these
IncRNAs achieve this pro-inflammatory effect through the NF- $\kappa B$ signaling pathway? The STAT pathway is well known to participate in the cell proliferation, apoptosis and immune modulation and plays a crucial role in the signal transduction of a great number of cytokines. ${ }^{144} \mathrm{M} 1$ microglia are characterized by the induction of STAT1 and NF- $\mathrm{KB}$ transcription factors, while the M2 type is related to the transcription factor STAT6. ${ }^{116}$ LncRNA SNHG15 increases neuronal damage and microglial inflammation by sponging miR-302a-3p as a competitive endogenous RNA, while this miRNA targets STAT1 and negatively regulates the NF- $\mathrm{KB}$ pathway. ${ }^{88}$ In addition, Kuai et al ${ }^{89}$ and Tian et al ${ }^{11}$ revealed that lncRNAs Snhg8 and THRIL regulate inflammation and microglia activation via SIRT1 and neuropilin-1 (NRP1), respectively, by regulating the NF-kB pathway. Thus, lncRNAs might contribute to regulating neuroinflammation and microglia activation by THRIL, NRP1, and STAT1, which further regulate the NF- $\mathrm{BB}$ pathway. Information regarding this aspect, however, is scarce.

\section{LncRNAs Regulate Inflammation Through the AKT and ERK Pathways Upon Stroke}

Akt includes three subtypes: Akt1, Akt2 and Akt3. ${ }^{145}$ Numerous scientists have recently focused on the protective effects of Akt by increasing phosphorylated Akt in
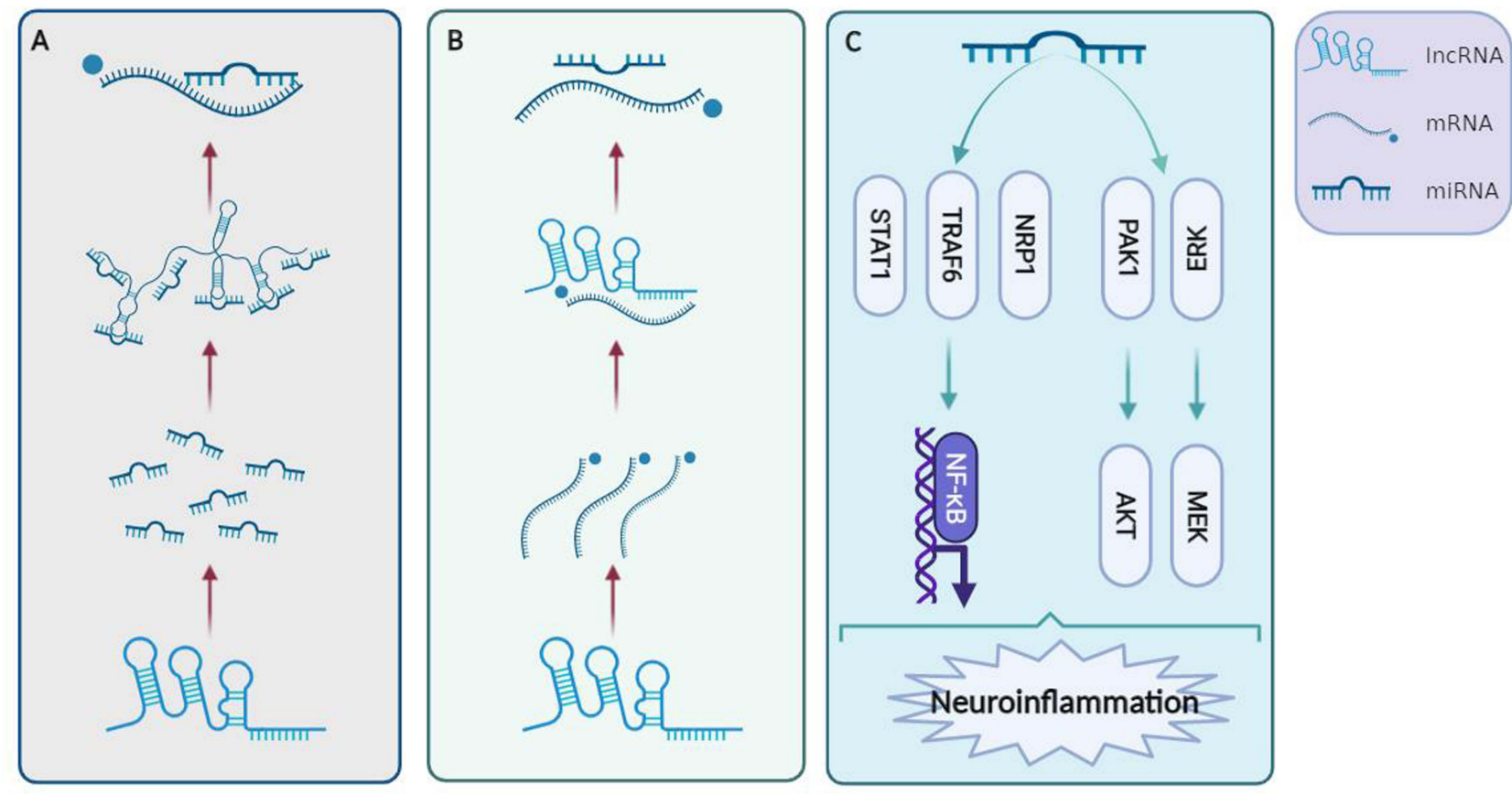

Figure 2 Signaling pathways that describe the process of inflammation regulation by the IncRNA-miRNA-mRNA axis. (A) LncRNAs have 'sponging-like effects' on miRNAs directly and target mRNAs. (B) Some IncRNAs can bind to mRNAs that compete with miRNAs directly. (C) LncRNAs can regulate inflammation through the NF- $K B$, AKT, and MEK pathways. Created with Biorender.com.

Abbreviations: ERK, extracellular signal-regulated kinase; MEK, mitogen-activated protein kinase; NF- $\mathrm{B}$, nuclear factor- $\mathrm{B}$; NRPI, neuropilin-I; STATI, signal transducer and activator of transcription I; PDKI, phosphoinositide dependent kinase-I; AKT, protein kinases B. 
stroke conditions. ${ }^{146}$ The Akt pathway has been shown to participate in neuronal survival and inflammation regulation after ischemic stroke, ${ }^{147}$ thus illustrating that pharmacological upregulation of Akt signaling might be a potential target for protecting the injured brain. Gao et al pointed out that IncRNA FAL1 has the potential to protect primary brain microvascular endothelial cells against OGD/R-induced endothelial inflammation by regulating the PAK1/AKT signaling pathway. ${ }^{85}$ Phosphorylated PI3K can convert Akt into phosphorylated Akt and activate the key subunit of NF- $\mathrm{KB}$ to phosphorylated p65, which leads to the nuclear entry of NF- $\mathrm{kB}$ and subsequently causes the genetic transcription of inflammatory factors. ${ }^{147}$ Silencing of lncRNA SNHG15 can decrease the levels of proinflammatory cytokines (TNF- $\alpha$ and IL-1 $\beta$ ) and apoptosis of N2a cells via sequestering the miR-18a and subsequently activating the extracellular signal-regulated kinase (ERK) signaling pathway. ${ }^{86}$ Similarly, lncRNA ANRIL knockdown can suppress mouse mesangial cell proliferation, inflammation and fibrosis via ERK pathways in a diabetic nephropathy model. ${ }^{148}$ Akt also participates in inhibiting cell apoptosis and reducing eNOS expression via the ERK pathway in a bilateral common carotid occlusion model. ${ }^{149}$

\section{Conclusion}

Neuroinflammation usually results in aberrant expression of numerous lncRNAs that exert important functions in epigenetic and transcriptional regulation of the expression of genes. LncRNAs can modulate inflammation by interacting with different signaling pathways, which offers an exceptional opportunity for adjuvant stroke treatment. A great amount of evidence illustrates that numerous IncRNAs can regulate microglial activation and polarization and modulate the inflammatory response in clinical and preclinical stroke studies. The IncRNA-microRNAmRNA axis is a key player in regulating inflammation upon ischemic stroke, and the NF- $\mathrm{KB}$ and AKT pathways are also essential. Although we have witnessed remarkable progress in our understanding of the vital role of lncRNAs in regulating neuroinflammation, many lncRNAs have not yet been functionally characterized and their molecular mechanisms are poorly known. Further efforts should be made to identify more inflammatory lncRNAs species that function under hypoxia. With a better understanding of the gene regulation modalities of IncRNAs, greater progress in this area can be made.

\section{Acknowledgements}

We thank the support of China Scholarship Council for Wenqiang Xin, Yongli Pan, Wei Wei and Tianyang Zheng.

\section{Disclosure}

Yongli Pan, Qingzheng Jiao, Wei Wei and Tianyang Zheng should be considered co-first authors. The authors declare that they have no competing interests.

\section{References}

1. Feigin V, Norrving B, Mensah G. Global burden of stroke. Circul Res. 2017;120(3):439-448. doi:10.1161/CIRCRESAHA.116.308413

2. Zhang SR, Phan T, Sobey C. Targeting the immune system for ischemic stroke. Trends Pharmacol Sci. 2021;42(2):96-105. doi:10.1016/j.tips.2020.11.010

3. Hacke W, Kaste M, Bluhmki E, et al. Thrombolysis with alteplase 3 to 4.5 hours after acute ischemic stroke. $N$ Engl $\mathrm{J} \mathrm{Med}$. 2008;359(13):1317-1329. doi:10.1056/NEJMoa0804656

4. Emsley H, Hopkins S. Acute ischaemic stroke and infection: recent and emerging concepts. Lancet Neurol. 2008;7 (4):341-353. doi:10.1016/S1474-4422(08)70061-9

5. Mccoll B, Allan S, Rothwell N. Systemic infection, inflammation and acute ischemic stroke. Neuroscience. 2009;158 (3):1049-1061. doi:10.1016/j.neuroscience.2008.08.019

6. Mccoll B, Rothwell N, Allan S. Systemic inflammatory stimulus potentiates the acute phase and $\mathrm{CXC}$ chemokine responses to experimental stroke and exacerbates brain damage via interleukin-1- and neutrophil-dependent mechanisms. $J$ Neurosci. 2007;27 (16):4403-4412. doi:10.1523/JNEUROSCI.5376-06.2007

7. Ma Y, Wang J, Wang Y, Yang G. The biphasic function of microglia in ischemic stroke. Prog Neurobiol. 2017;157:247-272.

8. Wen Y, Zhang H, Qin Z. Inflammatory mechanism in ischemic neuronal injury. Neurosci Bull. 2006;22(3):171-182.

9. Gan L, Liao S, Xing Y, Deng S. The regulatory functions of lncRNAs on angiogenesis following ischemic stroke. Front Mol Neurosci. 2020;13:613976. doi:10.3389/fnmol.2020.613976

10. Vasudeva K, Dutta A, Munshi A. Role of lncRNAs in the development of ischemic stroke and their therapeutic potential. Mol Neurobiol. 2021;58(8):3712-3728. doi:10.1007/s12035-021-02359-0

11. Tian J, Liu Y, Wang Z, et al. LncRNA Snhg8 attenuates microglial inflammation response and blood-brain barrier damage in ischemic stroke through regulating miR-425-5p mediated SIRT1/ NF-kB signaling. J Biochem Mol Toxicol. 2021;35(5):e22724. doi: $10.1002 / j b t .22724$

12. Disabato Damon J, Ning Q, Godbout Jonathan P. Neuroinflammation: the devil is in the details. $J$ Neurochem. 2016;139(Suppl 2):136-153. doi:10.1111/jnc.13607

13. Alawieh Ali LE, Farris TS. Targeted complement inhibition salvages stressed neurons and inhibits neuroinflammation after stroke in mice. Sci Transl Med. 2018;10:441.

14. Xu Q, Zhao B, Ye Y, et al. Relevant mediators involved in and therapies targeting the inflammatory response induced by activation of the NLRP3 inflammasome in ischemic stroke. J Neuroinflammation. 2021;18(1):123.

15. Weixiang C, Chao G, Hua F, Yujie C. Mitochondria: novel mechanisms and therapeutic targets for secondary brain injury after intracerebral hemorrhage. Front Aging Neurosci. 2020;12:615451.

16. Forrester Steven J, Kikuchi Daniel S, Hernandes Marina S, et al. Reactive oxygen species in metabolic and inflammatory signaling. Circ Res. 2018;122(6):877-902. doi:10.1161/ CIRCRESAHA.117.311401 
17. Radlinska Basia A, Ghinani Sasan A, Paul L, et al. Multimodal microglia imaging of fiber tracts in acute subcortical stroke. Ann Neurol. 2009;66(6):825-832. doi:10.1002/ana.21796

18. Jodie S, Erik N, Van Der Valk P, Sandra A. Inflammation in CNS neurodegenerative diseases. Immunology. 2018;154(2):204-219. doi:10.1111/imm. 12922

19. Jayaraj Richard L, Sheikh A, Rami B, Jalal Fakhreya Y, Rosenberg Gary A. Neuroinflammation: friend and foe for ischemic stroke. J Neuroinflammation. 2019;16(1):142.

20. Zhihong J, Rui L, Xiqun Z, et al. The involvement and therapy target of immune cells after ischemic stroke. Front Immunol. 2019;10:2167. doi:10.3389/fimmu.2019.02167

21. Wei C, Xuejiao D, Jie C, et al. STAT6/Arg1 promotes microglia/ macrophage efferocytosis and inflammation resolution in stroke mice. JCI Insight. 2019;4:20.

22. Levard D, Buendia I, Lanquetin A, Glavan M, Vivien D, Rubio M. Filling the gaps on stroke research: focus on inflammation and immunity. Behav Immun. 2021;91:649-667. doi:10.1016/ j.bbi.2020.09.025

23. Josef A, Costantino I. Inflammation and stroke: an overview. Neurotherapeutics. 2016;13(4):661-670. doi:10.1007/s13311016-0483-x

24. Liddelow Shane A, Guttenplan Kevin A, Clarke Laura E, et al. Neurotoxic reactive astrocytes are induced by activated microglia. Nature. 2017;541(7638):481-487. doi:10.1038/nature21029

25. Eileen G, Mathias G, Tim M. Danger signals in stroke and their role on microglia activation after ischemia. Ther Adv Neurol Disord. 2018;11:1756286418774254.

26. Andis K. Regulation of neuroimmune processes by damage- and resolution-associated molecular patterns. Neural Regen Res. 2021;16(3):423-429. doi:10.4103/1673-5374.293134

27. Li-Rong L, Jia-Chen L, Jin-Shuang B, Qin-Qin B, Gai-Qing W. Interaction of microglia and astrocytes in the neurovascular unit. Front Immunol. 2020;11:1024. doi:10.3389/fimmu.2020.01024

28. Koichiro H, Ako I, Yoshihisa T, et al. Dual microglia effects on blood brain barrier permeability induced by systemic inflammation. Nat Commun. 2019;10(1):5816. doi:10.1038/ s41467-019-13812-Z

29. Nocon MR, Luen SA, Aaron WG, et al. Profiling the mouse brain endothelial transcriptome in health and disease models reveals a core blood-brain barrier dysfunction module. Nat Neurosci. 2019;22(11):1892-1902. doi:10.1038/s41593-019-0497-x

30. An-Qi C, Zhi F, Xiao-Lu C, et al. Microglia-derived TNF- $\alpha$ mediates endothelial necroptosis aggravating blood brain-barrier disruption after ischemic stroke. Cell Death Dis. 2019;10(7):487. doi:10.1038/s41419-019-1716-9

31. Xiaoyan J, Andjelkovic Anuska V, Ling Z, et al. Blood-brain barrier dysfunction and recovery after ischemic stroke. Prog Neurobiol. 2018;163-164:144-171.

32. Yang-Wei FD, Yun-An L, Cheng Y-L, et al. Evidence that NF- $\kappa B$ and MAPK signaling promotes NLRP inflammasome activation in neurons following ischemic stroke. Mol Neurobiol. 2018;55 (2):1082-1096. doi:10.1007/s12035-017-0394-9

33. Weijie X, Ting Z, Dong X, et al. HMGB1-triggered inflammation inhibition of notoginseng leaf triterpenes against cerebral ischemia and reperfusion injury via MAPK and NF- $\mathrm{B}$ signaling pathways. Biomolecules. 2019;9:10.

34. Liwei T, Li J, Wang Y, Rui T. Anti-Neuroinflammatory effect of alantolactone through the suppression of the NF- $\kappa B$ and MAPK signaling pathways. Cells. 2019;8:7.

35. Hankey Graeme J. Stroke. Lancet. 2017;389(10069):641-654. doi:10.1016/S0140-6736(16)30962-X

36. Antoine D, Izaskun B, Damien L, et al. Immune responses and anti-inflammatory strategies in a clinically relevant model of thromboembolic ischemic stroke with reperfusion. Transl Stroke Res. 2020;11(3):481-495. doi:10.1007/s12975-019-00733-8
37. Kopp F, Mendell JT. Functional classification and experimental dissection of long noncoding RNAs. Cell. 2018;172(3):393-407.

38. Guo M, Xiao ZD, Dai Z, et al. The landscape of long noncoding RNA-involved and tumor-specific fusions across various cancers. Nucleic Acids Res. 2020;48(22):12618-12631. doi:10.1093/nar/ gkaa1119

39. Bar C, Chatterjee S, Thum T. Long noncoding RNAs in cardiovascular pathology, diagnosis, and therapy. Circulation. 2016;134 (19):1484-1499. doi:10.1161/CIRCULATIONAHA.116.023686

40. Kuo CC, Hanzelmann S, Senturk Cetin N, et al. Detection of RNA-DNA binding sites in long noncoding RNAs. Nucleic Acids Res. 2019;47(6):e32. doi:10.1093/nar/gkz037

41. Bao MH, Zhu SZ, Gao XZ, Sun HS, Feng ZP. Meta-analysis on the association between brain-derived neurotrophic factor polymorphism rs6265 and ischemic stroke, poststroke depression. J Stroke Cerebrovasc Dis. 2018;27(6):1599-1608. doi:10.1016/j. jstrokecerebrovasdis.2018.01.010

42. Feng L, Guo J, Ai F. Circulating long noncoding RNA ANRIL downregulation correlates with increased risk, higher disease severity and elevated pro-inflammatory cytokines in patients with acute ischemic stroke. J Clin Lab Anal. 2019;33(1):e22629.

43. Wang Y, Luo Y, Yao Y, et al. Silencing the lncRNA Maclpil in pro-inflammatory macrophages attenuates acute experimental ischemic stroke via LCP1 in mice. J Cereb Blood Flow Metab. 2020;40(4):747-759.

44. Chen R, Xu X, Huang L, Zhong W, Cui L. The regulatory role of long noncoding RNAs in different brain cell types involved in ischemic stroke. Front Mol Neurosci. 2019;12:61.

45. Raghavendar C, Mehta Suresh L, Raghu V. Non-coding RNAs and neuroprotection after acute CNS injuries. Neurochem Int. 2017;111:12-22.

46. Zhang X, Tang X, Liu K, Hamblin MH, Yin KJ. Long noncoding RNA Malat1 regulates cerebrovascular pathologies in ischemic stroke. J Neurosci. 2017;37(7):1797-1806.

47. Li Z, Li J, Tang N. Long noncoding RNA Malat1 is a potent autophagy inducer protecting brain microvascular endothelial cells against oxygen-glucose deprivation/reoxygenation-induced injury by sponging miR-26b and upregulating ULK2 expression. Neuroscience. 2017;354:1-10. doi:10.1016/j.neuroscience.2017.04.017

48. Dharap A, Nakka VP, Vemuganti R. Effect of focal ischemia on long noncoding RNAs. Stroke. 2012;43(10):2800-2802. doi:10.1161/STROKEAHA.112.669465

49. Guo D, Ma J, Yan L, et al. Down-regulation of Lncrna MALAT1 attenuates neuronal cell death through suppressing beclin1-dependent autophagy by regulating Mir-30a in cerebral ischemic stroke. Cell Physiol Biochem. 2017;43(1):182-194. doi:10.1159/000480337

50. Bhattarai S, Pontarelli F, Prendergast E, Dharap A. Discovery of novel stroke-responsive lncRNAs in the mouse cortex using genome-wide RNA-seq. Neurobiol Dis. 2017;108:204-212. doi:10.1016/j.nbd.2017.08.016

51. Wang SW, Liu Z, Shi ZS. Non-coding RNA in acute ischemic stroke: mechanisms, biomarkers and therapeutic targets. Cell Transplant. 2018;27(12):1763-1777. doi:10.1177/0963689718 806818

52. Wang J, Cao B, Han D, Sun M, Feng J. Long non-coding RNA H19 induces cerebral ischemia reperfusion injury via activation of autophagy. Aging Dis. 2017;8(1):71-84.

53. Zhu M, Li N, Luo P, et al. Peripheral blood leukocyte expression of IncRNA MIAT and its diagnostic and prognostic value in ischemic stroke. J Stroke Cerebrovasc Dis. 2018;27(2):326-337. doi:10.1016/j.jstrokecerebrovasdis.2017.09.009

54. Yan H, Rao J, Yuan J, et al. Long non-coding RNA MEG3 functions as a competing endogenous RNA to regulate ischemic neuronal death by targeting miR-21/PDCD4 signaling pathway. Cell Death Dis. 2017;8(12):3211. doi:10.1038/s41419-017-0047-y 
55. Chen S, Wang $M$, Yang $H$, et al. LncRNA TUG1 sponges microRNA-9 to promote neurons apoptosis by up-regulated Bcl2111 under ischemia. Biochem Biophys Res Commun. 2017;485(1):167-173.

56. Mehta SL, Kim T, Vemuganti R. Long noncoding RNA FosDT Promotes ischemic brain injury by interacting with REST-associated chromatin-modifying proteins. $J$ Neurosci. 2015;35(50):16443-16449.

57. Chen F, Zhang L, Wang E, Zhang C, Li X.LncRNA GAS5 regulates ischemic stroke as a competing endogenous RNA for miR-137 to regulate the Notch1 signaling pathway. Biochem Biophys Res Commun. 2018;496(1):184-190.

58. Wu Z, Wu P, Zuo X, et al. LncRNA-N1LR Enhances neuroprotection against ischemic stroke probably by inhibiting p53 phosphorylation. Mol Neurobiol. 2017;54(10):7670-7685. doi:10.1007/s12035-016-0246-Z

59. Xu Q, Deng F, Xing Z, et al. Long non-coding RNA C2datl regulates CaMKIIdelta expression to promote neuronal survival through the NF-kappaB signaling pathway following cerebral ischemia. Cell Death Dis. 2016;7:e2173.

60. Zhang L, Luo X, Chen F, et al. LncRNA SNHG1 regulates cerebrovascular pathologies as a competing endogenous RNA through HIF-1alpha/VEGF signaling in ischemic stroke. $J$ Cell Biochem. 2018;119(7):5460-5472. doi:10.1002/jcb.26705

61. Wei R, Zhang L, Hu W, Wu J, Zhang W. Long non-coding RNA AK038897 aggravates cerebral ischemia/reperfusion injury via acting as a ceRNA for miR-26a-5p to target DAPK1. Exp Neurol. 2019;314:100-110. doi:10.1016/j.expneurol.2019.01.009

62. Bihong L, Ruimian C, Feng L, et al. Long noncoding RNA HOTTIP promotes endothelial cell proliferation and migration via activation of the Wnt/ $\beta$-catenin pathway. $J$ Cell Biochem. 2017;119(3):2797-2805.

63. Kumar S, Williams D, Sur S, Wang JY, Jo H. Role of flow-sensitive microRNAs and long noncoding RNAs in vascular dysfunction and atherosclerosis. Vascul Pharmacol. 2019;114:76-92.

64. Datta A, Sarmah D, Mounica L, et al. Cell death pathways in ischemic stroke and targeted pharmacotherapy. Transl Stroke Res. 2020;11(6):1185-1202. doi:10.1007/s12975-020-00806-Z

65. Radak D, Katsiki N, Resanovic I, et al. Apoptosis and acute brain ischemia in ischemic stroke. Curr Vasc Pharmacol. 2017;15 (2):115-122. doi:10.2174/1570161115666161104095522

66. Fan J, Saft M, Sadanandan N, et al. LncRNAs stand as potent biomarkers and therapeutic targets for stroke. Front Aging Neurosci. 2020;12:594571.

67. Wang Z, Li X, Huang L, et al. Long non-coding RNAs (lncRNAs), a new target in stroke. Cell Mol Neurobiol. 2020. doi:10.1007/s10571-020-00954-8

68. Chen F, Zhang L, Wang E, Zhang C, Li X. LncRNA GAS5 regulates ischemic stroke as a competing endogenous RNA for miR-137 to regulate the Notch1 signaling pathway. Biochem Biophy Res Commun. 2018;496(1):184-190.

69. Chen S, Wang $\mathrm{M}$, Yang $\mathrm{H}$, et al. LncRNA TUG1 sponges microRNA-9 to promote neurons apoptosis by up-regulated Bcl2111 under ischemia. Biochem Biophys Res Commun. 2017;485(1):167-173.

70. Kuwana T, Bouchier-Hayes L, Chipuk J, et al. BH3 domains of $\mathrm{BH} 3$-only proteins differentially regulate Bax-mediated mitochondrial membrane permeabilization both directly and indirectly. Mol Cell. 2005;17(4):525-535. doi:10.1016/j. molcel.2005.02.003

71. Jing H, Liu L, Jia Y, Yao H, Ma F. Overexpression of the long non-coding RNA Oprm1 alleviates apoptosis from cerebral ischemia-reperfusion injury through the Oprm1/miR-155/GATA3 axis. Artif Cells Nanomed Biotechnol. 2019;47(1):2431-2439. doi:10.1080/21691401.2019.1626408
72. Yin $\mathrm{D}, \mathrm{Xu} \mathrm{F}, \mathrm{Lu} \mathrm{M}, \mathrm{Li} \mathrm{X}$. Long non-coding RNA RMST promotes oxygen-glucose deprivation-induced injury in brain microvascular endothelial cells by regulating miR-204-5p/VCAM1 axis. Life Sci. 2021;119244. doi:10.1016/j.lfs.2021.119244

73. Heydari E, Alishahi M, Ghaedrahmati F, Winlow W, Khoshnam SE, Anbiyaiee A. The role of non-coding RNAs in neuroprotection and angiogenesis following ischemic stroke. Metab Brain Dis. 2020;35(1):31-43. doi:10.1007/s11011-01900485-2

74. Yan G, Zhao H, Hong X. LncRNA MACC1-AS1 attenuates microvascular endothelial cell injury and promotes angiogenesis under hypoxic conditions via modulating miR-6867-5p/TWIST1 in human brain microvascular endothelial cells. Ann Transl Med. 2020;8(14):876. doi:10.21037/atm-20-4915

75. Liu J, Li Q, Zhang KS, et al. Downregulation of the long non-coding RNA Meg3 promotes angiogenesis after ischemic brain injury by activating notch signaling. Mol Neurobiol. 2017;54(10):8179-8190. doi:10.1007/s12035-016-0270-z

76. Yin WL, Yin WG, Huang BS, Wu LX. LncRNA SNHG12 inhibits miR-199a to upregulate SIRT1 to attenuate cerebral ischemia/ reperfusion injury through activating AMPK signaling pathway. Neurosci Lett. 2019;690:188-195. doi:10.1016/j.neulet.20 18.08 .026

77. Zhao M, Wang J, Xi X, Tan N, Zhang L. SNHG12 promotes angiogenesis following ischemic stroke via regulating miR-150/ VEGF pathway. Neuroscience. 2018;390:231-240. doi:10.1016/j. neuroscience.2018.08.029

78. Pham TP, Bink DI, Stanicek L, et al. Long non-coding RNA aerrie controls DNA damage repair via YBX1 to maintain endothelial cell function. Front Cell Dev Biol. 2020;8:619079. doi:10.3389/fcell.2020.619079

79. Xu Z, Yan Y, Qian L, Gong Z. Long non-coding RNAs act as regulators of cell autophagy in diseases. Oncol Rep. 2017;37 (3):1359-1366. doi:10.3892/or.2017.5416

80. Zhou F, Wang M, Ju J, et al. Schizandrin A protects against cerebral ischemia-reperfusion injury by suppressing inflammation and oxidative stress and regulating the AMPK/Nrf2 pathway regulation. Am J Transl Res. 2019;11(1):199-209.

81. Mehta S, Kim T, Vemuganti R. Long noncoding RNA FosDT promotes ischemic brain injury by interacting with REST-associated chromatin-modifying proteins. $J$ Neurosci. 2015;35(50):16443-16449. doi:10.1523/JNEUROSCI.294315.2015

82. Wang J, Cao B, Han D, Sun M, Feng J. Long non-coding RNA $\mathrm{H} 19$ induces cerebral ischemia reperfusion injury via activation of autophagy. Aging Dis. 2017;8(1):71-84.

83. Yu S, Yu M, He X, Wen L, Bu Z, Feng J. KCNQ1OT1 promotes autophagy by regulating $\mathrm{miR}-200 \mathrm{a} / \mathrm{FOXO} 3 / \mathrm{ATG} 7$ pathway in cerebral ischemic stroke. Aging Cell. 2019;18(3):e12940. doi:10.1111/acel.12940

84. Cao D, Liu M, Duan R, et al. The lncRNA Malat1 functions as a ceRNA to contribute to berberine-mediated inhibition of HMGB1 by sponging miR-181c-5p in poststroke inflammation. Acta Pharmacologica Sinica. 2020;41(1):22-33. doi:10.1038/ s41401-019-0284-y

85. Gao M, Fu J, Wang Y. The lncRNA FAL1 protects against hypoxia-reoxygenation- induced brain endothelial damages through regulating PAK1. $J$ Bioenergetics Biomembranes. 2020;52(1):17-25. doi:10.1007/s10863-019-09819-2

86. Guo T, Liu Y, Ren X, Wang W, Liu H. Promoting role of long non-coding RNA small nucleolar RNA host Gene 15 (SNHG15) in neuronal injury following ischemic stroke via the MicroRNA-18a/CXC chemokine Ligand 13 (CXCL13)/ERK/ MEK axis. Med Sci Monitor. 2020;26:e923610. doi:10.12659/ MSM.923610 
87. Hao C, Chen S. Knockdown of IncRNA TTTY15 alleviates ischemia/reperfusion-induced inflammation and apoptosis of PC12 cells by targeting miR-766-5p. Exp Ther Med. 2021;21 (5):511. doi:10.3892/etm.2021.9942

88. Hu C, Li C, Ma Q, et al. Inhibition of long noncoding RNA SNHG15 Ameliorates hypoxia/ischemia-induced neuronal damage by regulating miR-302a-3p/STAT1/NF- $\mathrm{kB}$ axis. Yonsei Med J. 2021;62(4):325-337. doi:10.3349/ymj.2021.62.4.325

89. Kuai F, Zhou L, Zhou J, Sun X, Dong W. Long non-coding RNA THRIL inhibits miRNA-24-3p to upregulate neuropilin-1 to aggravate cerebral ischemia-reperfusion injury through regulating the nuclear factor $\mathrm{\kappa B}$ p65 signaling. Aging. 2021;13 (6):9071-9084. doi:10.18632/aging.202762

90. Li H, Tang C, Wang D. LncRNA H19 promotes inflammatory response induced by cerebral ischemia-reperfusion injury through regulating the miR-138-5p-p65 axis. Biochem Cell Biol/Biochimie Et Biologie Cellulaire. 2020;98(4):525-536. doi:10.1139/bcb2019-0281

91. Liang J, Wang Q, Li J, Guo T, Yu D. Long non-coding RNA MEG3 promotes cerebral ischemia-reperfusion injury through increasing pyroptosis by targeting miR-485/AIM2 axis. Exp Neurol. 2020;325:113139. doi:10.1016/j.expneurol.2019.113139

92. Lv L, Xi HP, Huang JC, Zhou XY. LncRNA SNHG1 alleviated apoptosis and inflammation during ischemic stroke by targeting miR-376a and modulating CBS/HS pathway. Int $J$ Neurosci. 2020;1-11:2020. doi:10.1080/00207454.2020.1782904

93. Ruan W, Li J, Xu Y, et al. MALAT1 up-regulator polydatin protects brain microvascular integrity and ameliorates stroke through C/EBP $\beta / \mathrm{MALAT} 1 / \mathrm{CREB} / \mathrm{PGC}-1 \alpha / \mathrm{PPAR} \gamma$ pathway. Cell Mol Neurobiol. 2019;39(2):265-286. doi:10.1007/s10571-01800646-4

94. Wang Y, Luo Y, Yao Y, et al. MaclpilSilencing the lncRNA in pro-inflammatory macrophages attenuates acute experimental ischemic stroke via LCP1 in mice. $J$ Cerebral Blood Flow Metabol. 2020;40(4):747-759.

95. Wang C, Hu F. Long noncoding RNA SOX2OT silencing alleviates cerebral ischemia-reperfusion injury via miR-135a-5pmediated NR3C2 inhibition. Brain Res Bull. 2021;173:193-202.

96. Wang J, Fu Z, Wang M, Lu J, Yang H, Lu H. Knockdown of XIST attenuates cerebral ischemia/reperfusion injury through regulation of miR-362/ROCK2 axis. Neurochem Res. 2021;46 (8):2167-2180. doi:10.1007/s11064-021-03354-6

97. Zhang X, Tang X, Liu K, Hamblin M, Yin K. Long noncoding RNA Malat1 regulates cerebrovascular pathologies in ischemic stroke. J Neurosci. 2017;37(7):1797-1806.

98. Zhang Y, Zhang Y. lncRNA ZFAS1 improves neuronal injury and inhibits inflammation, oxidative stress, and apoptosis by sponging miR-582 and upregulating NOS3 expression in cerebral ischemia/ reperfusion injury. Inflammation. 2020;43(4):1337-1350. doi:10.1007/s10753-020-01212-1

99. Zhang H, Ouyang B, Ji X, Liu M. Gastrodin alleviates cerebral ischaemia/reperfusion injury by inhibiting pyroptosis by regulating the lncRNA NEAT1/miR-22-3p axis. Neurochem Res. 2021;46(7):1747-1758. doi:10.1007/s11064-021-03285-2

100. Lijuan F, Jun G, Fen A. Circulating long noncoding RNA ANRIL downregulation correlates with increased risk, higher disease severity and elevated pro-inflammatory cytokines in patients with acute ischemic stroke. $J$ Clin Lab Anal. 2019;33(1):e22629.

101. Li P, Duan S, Fu A. Long noncoding RNA NEAT1 correlates with higher disease risk, worse disease condition, decreased miR-124 and miR-125a and predicts poor recurrence-free survival of acute ischemic stroke. J Clin Lab Anal. 2020;34(2):e23056.

102. Ren H, Feng W, Bin L, Zhiyuan S, Dacheng Q. Association of circulating long non-coding RNA MALAT1 in diagnosis, disease surveillance, and prognosis of acute ischemic stroke. Braz J Med Biol Res. 2020;53(12):e9174. doi:10.1590/1414-431x20209174
103. Ren B, Song Z, Chen L, Niu X, Feng Q. Long non-coding RNA UCA1 correlates with elevated disease severity, Th17 cell proportion, inflammatory cytokines, and worse prognosis in acute ischemic stroke patients. J Clin Lab Anal. 2021;35(3):e23697.

104. Ming Y, Yue L, Dan W, Qiuxia Z, Yang L, Chunsheng Y. KCNQ1OT1 exacerbates ischemia-reperfusion injury through targeted Inhibition of miR-140-3P. Inflammation. 2020;43 (5):1832-1845. doi:10.1007/s10753-020-01257-2

105. Zhang Y, Niu C. The correlation of long non-coding RNA intersectin 1-2 with disease risk, disease severity, inflammation, and prognosis of acute ischemic stroke. J Clin Lab Anal. 2020;34(2): e23053.

106. Chen Y, Liu W, Chen M, Sun Q, Chen H, Li Y. Up-regulating lncRNA OIP5-AS1 protects neuron injury against cerebral hypoxia-ischemia induced inflammation and oxidative stress in microglia/macrophage through activating CTRP3 via sponging miR-186-5p. Int Immunopharmacol. 2021;92:107339. doi:10.1016/j.intimp.2020.107339

107. Chen J, Jin J, Zhang X, et al. Microglial lnc-U90926 facilitates neutrophil infiltration in ischemic stroke via MDH2/CXCL2 axis. Mol Ther. 2021. doi:10.1016/j.ymthe.2021.04.025

108. Li T, Luo Y, Zhang P, et al. MEG3 regulates microglial polarization through KLF4 to affect cerebral ischemia-reperfusion injury. $J$ Appl Physiol. 2020;129(6):1460-1467. doi:10.1152/ japplphysiol.00433.2020

109. Ni X, Su Q, Xia W, et al. Knockdown lncRNA NEAT1 regulates the activation of microglia and reduces AKT signaling and neuronal apoptosis after cerebral ischemic reperfusion. Sci Rep. 2020;10(1):19658.

110. Qi X, Shao M, Sun H, Shen Y, Meng D, Huo W. Long non-coding RNA SNHG14 promotes microglia activation by regulating miR-145-5p/PLA2G4A in cerebral infarction. Neuroscience. 2017;348:98-106. doi:10.1016/j.neuroscience.2017.02.002

111. Wang L, Zhou H. LncRNA MALAT1 promotes high glucose-induced inflammatory response of microglial cells via provoking MyD88/IRAK1/TRAF6 signaling. Sci Rep. 2018;8 (1):8346

112. Wang $\mathrm{H}$, Liao $\mathrm{S}, \mathrm{Li} \mathrm{H}$, Chen $\mathrm{Y}$, Yu J. Long non-coding RNA TUG1 sponges Mir-145a-5p to regulate microglial polarization after oxygen-glucose deprivation. Front Mol Neurosci. 2019;12:215. doi: $10.3389 /$ fnmol.2019.00215

113. Zhang B, Li Q, Jia S, Li F, Li Q, Li J. LincRNA-EPS in biomimetic vesicles targeting cerebral infarction promotes inflammatory resolution and neurogenesis. J Transl Med. 2020;18 (1):110. doi:10.1186/s12967-020-02278-Z

114. Wang L, Zheng Y, Zhou H, Zhang X, Wu P, Zhu S. LncRNAFender protects against the ubiquitination and degradation of NLRC4 protein through HERC2 to regulate the pyroptosis of microglia. Mol Med. 2021;27(1):39. doi:10.1186/s10020-02100299-y

115. Zhang X, Zhu X, Ji B, et al. LncRNA-1810034E14Rik reduces microglia activation in experimental ischemic stroke. J Neuroinflammation. 2019;16(1):75. doi:10.1186/s12974-0191464-x

116. Zhang S, Sun W-C, Liang Z-D, et al. LncRNA SNHG4 attenuates inflammatory responses by sponging miR-449c-5p and up-regulating STAT6 in microglial during cerebral ischemia-reperfusion injury. Drug Design Develop Ther. 2020;14:3683-3695. doi:10.2147/DDDT.S245445

117. Zhang G, Li T, Chang X, Xing J. Long noncoding RNA SNHG14 promotes ischemic brain injury via regulating miR-199b/AQP4 axis. Neurochem Res. 2021;46(5):1280-1290.

118. Xu J, Wang C, Meng F, Xu P. Long noncoding RNA H19 inhibition ameliorates oxygen glucose deprivation induced cell apoptosis and inflammatory cytokine expression by regulating the microRNA29b/SIRT1/PGC1alpha axis. Mol Med Rep. 2021;23:2. 
119. Zhong Y, Yu C, Qin W. LncRNA SNHG14 promotes inflammatory response induced by cerebral ischemia/reperfusion injury through regulating miR-136-5p /ROCK1. Cancer Gene Ther. 2019;26(7-8):234-247. doi:10.1038/s41417-018-0067-5

120. Wen Y, Yu Y, Fu X. LncRNA Gm4419 contributes to OGD/R injury of cerebral microglial cells via IkappaB phosphorylation and NF-kappaB activation. Biochem Biophys Res Commun. 2017;487(4):923-929. doi:10.1016/j.bbrc.2017.05.005

121. Wang J, Zhao H, Fan Z, et al. Long noncoding RNA H19 promotes neuroinflammation in ischemic stroke by driving histone deacetylase 1-dependent M1 microglial polarization. Stroke. 2017;48(8):2211-2221. doi:10.1161/STROKEAHA.117.017387

122. Wang LQ, Zhou HJ. LncRNA MALAT1 promotes high glucose-induced inflammatory response of microglial cells via provoking MyD88/IRAK1/TRAF6 signaling. Sci Rep. 2018;8 (1):8346.

123. Ren W, Yang X. Pathophysiology of long non-coding RNAs in ischemic stroke. Front Mol Neurosci. 2018;11:96. doi:10.3389/ fnmol.2018.00096

124. Hu X, Leak R, Shi Y, et al. Microglial and macrophage polarization - new prospects for brain repair. Nat Rev Neurol. 2015;11 (1):56-64. doi:10.1038/nrneurol.2014.207

125. Iadecola $\mathrm{C}$, Anrather J. The immunology of stroke: from mechanisms to translation. Nat Med. 2011;17(7):796-808. doi:10.1038/ nm.2399

126. Jin $\mathrm{R}$, Yang G, Li G. Inflammatory mechanisms in ischemic stroke: role of inflammatory cells. J Leukocyte Biol. 2010;87 (5):779-789. doi:10.1189/jlb.1109766

127. Tang Y, Le W. Differential roles of M1 and M2 microglia in neurodegenerative diseases. Mol Neurobiol. 2016;53 (2):1181-1194. doi:10.1007/s12035-014-9070-5

128. Cheng Q, Shen Y, Cheng Z, et al. Achyranthes bidentata polypeptide $\mathrm{k}$ suppresses neuroinflammation in BV2 microglia through Nrf2-dependent mechanism. Ann Transl Med. 2019;7 (20):575. doi:10.21037/atm.2019.09.07

129. Zhang L, Zhang J, You Z. Switching of the microglial activation phenotype is a possible treatment for depression disorder. Front Cell Neurosc. 2018;12:306.

130. Ma L, Niu W, Lv J, Jia J, Zhu M, Yang S. PGC-1 $\alpha$-mediated mitochondrial biogenesis is involved in cannabinoid Receptor 2 agonist AM1241-induced microglial phenotype amelioration. Cell Mol Neurobiol. 2018;38(8):1529-1537. doi:10.1007/s10571-018-0628-Z

131. Zhang S, Sun WC, Liang ZD, et al. LncRNA SNHG4 attenuates inflammatory responses by sponging miR-449c-5p and up-regulating STAT6 in microglial during cerebral ischemia-reperfusion injury. Drug Des Devel Ther. 2020;14:3683-3695.

132. Zhang G, Li T, Chang X, Xing J. Long noncoding RNA SNHG14 promotes ischemic brain injury via regulating miR-199b/AQP4 axis. Neurochem Res. 2021;46(5):1280-1290.

133. Ni X, Su Q, Xia W, et al. Knockdown lncRNA NEAT1 regulates the activation of microglia and reduces AKT signaling and neuronal apoptosis after cerebral ischemic reperfusion. Sci Rep. 2020;10(1): 19658

134. Tianhao L, Yuru L, Peng Z, et al. LncRNA MEG3 regulates microglial polarization through KLF4 to affect cerebral ischemia-reperfusion injury. $J$ Appl Physiol. 2020;129 (6): 1460-1467.

135. Xinyue D, Jin G, Yang ZC, Christopher H, Marcos F, Zhenjia W. Neutrophil membrane-derived nanovesicles alleviate inflammation to protect mouse brain injury from ischemic stroke. ACS Nano. 2019;13(2):1272-1283
136. Mei-Hua B, Vivian S, Yang Burton B, Shu-Zhen Z, Hong-Shuo S, Zhong-Ping F. Long non-coding RNAs in ischemic stroke. Cell Death Dis. 2018;9(3):281. doi:10.1038/s41419-018-0282-x

137. Xiong W, Qu Y, Chen H, Qian J. Insight into long noncoding RNA-miRNA-mRNA axes in myocardial ischemia-reperfusion injury: the implications for mechanism and therapy. Epigenomics. 2019;11(15):1733-1748. doi:10.2217/epi-20190119

138. He L, Chen Y, Hao S, Qian J. Uncovering novel landscape of cardiovascular diseases and therapeutic targets for cardioprotection via long noncoding RNA-miRNA-mRNA axes. Epigenomics. 2018;10(5):661-671. doi:10.2217/epi-2017-0176

139. Archer K, Broskova Z, Bayoumi A, et al. Long non-coding RNAs as master regulators in cardiovascular diseases. Int $J \mathrm{Mol} \mathrm{Sci}$. 2015;16(10):23651-23667. doi:10.3390/ijms161023651

140. Zhong Y, Yu C, Qin W. LncRNA SNHG14 promotes inflammatory response induced by cerebral ischemia/reperfusion injury through regulating miR-136-5p /ROCK1. Cancer Gene Ther. 2019;26:234-247).

141. Xu J, Wang C, Meng F, Xu P. Long non-coding RNA H19 inhibition ameliorates oxygen-glucose deprivation-induced cell apoptosis and inflammatory cytokine expression by regulating the microRNA-29b/SIRT1/PGC-1 $\alpha$ axis. Mol Med Rep. 2021;23:2.

142. Lv Y, Tan J, Miao Y, Zhang Q. The role of microvesicles and its active molecules in regulating cellular biology. $J$ Cell Mol Med. 2019;23(12):7894-7904. doi:10.1111/jcmm. 14667

143. Zhao R, Ying M, Gu S, et al. Cysteinyl leukotriene Receptor 2 is involved in inflammation and neuronal damage by mediating microglia M1/M2 polarization through NF- $\mathrm{kB}$ pathway. Neuroscienc. 2019;422:99-118. doi:10.1016/j.neuroscience.20 19.10 .048

144. Lawrence T, Natoli G. Transcriptional regulation of macrophage polarization: enabling diversity with identity. Nat Rev Immunol. 2011;11(11):750-761. doi:10.1038/nri3088

145. Hers I, Vincent E, Tavaré J. Akt signalling in health and disease. Cell Signalling. 2011;23(10):1515-1527. doi:10.1016/j. cellsig.2011.05.004

146. Gao X, Zhang H, Takahashi T, et al. The Akt signaling pathway contributes to postconditioning's protection against stroke; the protection is associated with the MAPK and PKC pathways. $J \quad$ Neurochem. 2008;105(3):943-955. doi:10.1111/j.14714159.2008.05218.x

147. Lv H, Li J, Che Y. CXCL8 gene silencing promotes neuroglial cells activation while inhibiting neuroinflammation through the $\mathrm{PI} 3 \mathrm{~K} / \mathrm{Akt} / \mathrm{NF}-\kappa \mathrm{K}$-signaling pathway in mice with ischemic stroke. J Cell Physiol. 2019;234(5):7341-7355. doi:10.1002/ jcp. 27493

148. Fang X, Hu J, Zhou H. Knock-down of long non-coding RNA ANRIL suppresses mouse mesangial cell proliferation, fibrosis, inflammation via regulating $\mathrm{Wnt} / \beta$-Catenin and MEK/ERK pathways in diabetic nephropathy. Exp Clin Endocrinol Diabetes. 2020. doi:10.1055/a-1185-9283

149. Stanojlović M, Guševac Stojanović I, Zarić M, et al. Progesterone protects prefrontal cortex in rat model of permanent bilateral common carotid occlusion via progesterone receptors and Akt/ Erk/eNOS. Cell Mol Neurobiol. 2020;40(5):829-843. doi:10.1007/s10571-019-00777-2 


\section{Publish your work in this journal}

The Journal of Inflammation Research is an international, peerreviewed open-access journal that welcomes laboratory and clinical findings on the molecular basis, cell biology and pharmacology of inflammation including original research, reviews, symposium reports, hypothesis formation and commentaries on: acute/chronic inflammation; mediators of inflammation; cellular processes; molecular mechanisms; pharmacology and novel anti-inflammatory drugs; clinical conditions involving inflammation. The manuscript management system is completely online and includes a very quick and fair peerreview system. Visit http://www.dovepress.com/testimonials.php to read real quotes from published authors. 